\title{
Urokinase-Type Plasminogen Activator Protects Cerebral Cortical Neurons from Soluble A $\beta$-Induced Synaptic Damage
}

\author{
${ }^{\text {CD Ariel Diaz, }}{ }^{1}$ Paola Merino, ${ }^{1}$ Ji-Dong Guo, ${ }^{2,3}$ Manuel A. Yepes, ${ }^{1}$ Patrick McCann, ${ }^{1}$ Tapasya Katta, ${ }^{1}$ \\ Elise M. Tong, ${ }^{1}$ Enrique Torre, ${ }^{1}{ }^{\text {DO }}$ Srikant Rangaraju, ${ }^{4}$ and ${ }^{(D}$ Manuel Yepes ${ }^{1,4,5}$ \\ ${ }^{1}$ Division of Neuropharmacology and Neurologic Diseases, Yerkes National Primate Research Center, Atlanta, Georgia 30329, ${ }^{2}$ Silvio O. Conte \\ Center for Oxytocin and Social Cognition \& Center for Translational Social Neuroscience, Yerkes National Primate Research Center, Atlanta, \\ Georgia 30329, ${ }^{3}$ Department of Psychiatry and Behavioral Sciences, Emory University, Atlanta, Georgia 30329, ${ }^{4}$ Department of Neurology, Emory \\ University, Atlanta, Georgia 30329, and ${ }^{5}$ Department of Neurology, Veterans Affairs Medical Center, Atlanta, Georgia 30033
}

Soluble amyloid $\beta$ (A $\beta$ )-induced synaptic dysfunction is an early event in the pathogenesis of Alzheimer's disease (AD) that precedes the deposition of insoluble $A \beta$ and correlates with the development of cognitive deficits better than the number of plaques. The mammalian plasminogen activation (PA) system catalyzes the generation of plasmin via two activators: tissuetype (tPA) and urokinase-type (uPA). A dysfunctional tPA-plasmin system causes defective proteolytic degradation of A $\beta$ plaques in advanced stages of AD. In contrast, it is unknown whether UPA and its receptor (uPAR) contribute to the pathogenesis of this disease. Neuronal cadherin (NCAD) plays a pivotal role in the formation of synapses and dendritic branches, and A $\boldsymbol{\beta}$ decreases its expression in cerebral cortical neurons. Here we show that neuronal uPA protects the synapse from the harmful effects of soluble $\mathrm{A} \beta$. However, A $\beta$-induced inactivation of the eukaryotic initiation factor $2 \alpha$ halts the transcription of uPA mRNA, leaving unopposed the deleterious effects of $A \beta$ on the synapse. In line with these observations, the synaptic abundance of $u P A$, but not uPAR, is decreased in the frontal cortex of $\mathrm{AD}$ patients and $5 \mathrm{XFAD}$ mice, and in cerebral cortical neurons incubated with soluble $\mathrm{A} \beta$. We found that uPA treatment increases the synaptic expression of NCAD by a uPAR-mediated plasmin-independent mechanism, and that uPA-induced formation of NCAD dimers protects the synapse from the harmful effects of soluble A $\beta$ oligomers. These data indicate that $\mathrm{A} \beta$-induced decrease in the synaptic abundance of uPA contributes to the development of synaptic damage in the early stages of $\mathrm{AD}$.

Key words: Alzheimer's disease; plasmin; plasminogen system; urokinase

Significance Statement

Soluble amyloid $\beta$ (A $\beta$ )-induced synaptic dysfunction is an early event in the pathogenesis of cognitive deficits in Alzheimer's disease (AD). We found that neuronal urokinase-type (uPA) protects the synapse from the deleterious effects of soluble $\mathrm{A} \beta$. However, $\mathrm{A} \beta$-induced inactivation of the eukaryotic initiation factor $2 \alpha$ decreases the synaptic abundance of $\mathrm{uPA}$, leaving unopposed the harmful effects of $\mathrm{A} \beta$ on the synapse. In line with these observations, the synaptic expression of $\mathrm{uPA}$ is decreased in the frontal cortex of $\mathrm{AD}$ brains and $5 \mathrm{xFAD}$ mice, and $\mathrm{uPA}$ treatment abrogates the deleterious effects of $\mathrm{A} \beta$ on the synapse. These results unveil a novel mechanism of $\mathrm{A} \beta$-induced synaptic dysfunction in $\mathrm{AD}$ patients, and indicate that recombinant $\mathrm{UPA}$ is a potential therapeutic strategy to protect the synapse before the development of irreversible brain damage.

Received Nov. 25, 2019; revised Mar. 20, 2020; accepted Apr. 13, 2020.

Author contributions: A.D. and M.Y. designed research; A.D., P. Merino, J.-D.G., M.A.Y., P. McCann, T.K.,

E.M.T., and E.T. performed research; A.D. wrote the first draft of the paper; S.R. contributed unpublished reagents/analytic tools; S.R. and M.Y. edited the paper; M.Y. analyzed data; M.Y. wrote the paper.

This work was supported in part by National Institutes of Health Grant NS-NS091201 to M.Y. and Grant K08-NS099474-01 to S.R., Veterans Administration Merit Award I01BX003441 to M.Y., and American Heart Association Post-Doctoral Fellowship Grant 19P0ST34380009 to A.D.

The authors declare no competing financial interests.

Correspondence should be addressed to Manuel Yepes at myepes@emory.edu.

https://doi.org/10.1523/JNEUROSCI.2804-19.2020

Copyright $\odot 2020$ the authors

\section{Introduction}

Synaptic dysfunction is an early event in the pathogenesis of Alzheimer's disease (AD) (Davies et al., 1987; Selkoe, 2002) that precedes the deposition of amyloid $\beta$ (A $\beta$ ) (Martin et al., 1994; Hsia et al., 1999) and correlates with the severity of cognitive deficits better than the number of plaques (DeKosky and Scheff, 1990; Terry et al., 1991; Jacobsen et al., 2006). Thus, understanding the pathophysiology of synaptic injury in the early stages of $\mathrm{AD}$ is crucial for the discovery of therapeutic 
strategies to protect the synapse before the development of irreversible brain damage.

The $\mathrm{A} \beta$ is derived from the cleavage of the amyloid precursor protein by $\beta$ - and $\gamma$-secretase (Selkoe et al., 1996). The predominant isoforms of the $\mathrm{A} \beta$ peptide are $\mathrm{A} \beta \quad 1-40$ and $\mathrm{A} \beta \quad 1-42$ (Plant et al., 2003); and although in the early stages of AD both are soluble, at later stages insoluble forms are deposited into diffuse plaques (Kawarabayashi et al., 2001). It was initially believed that fibrillar $\mathrm{A} \beta$ accumulated in plaques was toxic to the synapse. However, subsequent studies showed that this is not the case, and instead that soluble nonfibrillar $\mathrm{A} \beta$ is more toxic than the fibrillar forms (Lambert et al., 1998). In line with these observations, soluble $\mathrm{A} \beta$ oligomers have a harmful impact on synaptic plasticity and the composition and function of axonal boutons (He et al., 2019) and dendritic spines (Lacor et al., 2007; Shankar et al., 2007).

The plasminogen activation (PA) system is assembled by a cascade of enzymes and their inhibitors that catalyze the generation of plasmin. There are two mammalian plasminogen activators: tissue-type (tPA) and urokinase-type (uPA) (Collen, 1999). A dysfunctional tPA-plasminogen system in advanced stages of $\mathrm{AD}$ has been linked to defective plasmin-induced cleavage of $\mathrm{A} \beta$-containing plaques (Tucker et al., 2000) and A $\beta$-induced neurodegeneration (Melchor et al., 2003). In contrast, although some studies indicate that $\mathrm{A} \beta$ induces the release of uPA in cell cultures (Davis et al., 2003), the role of this plasminogen activator in the pathogenesis of $\mathrm{AD}$ is unknown.

Neuronal cadherin (NCAD) is a Type I cadherin that in the mature brain is found in glutamatergic synapses of the II/III and V cortical layers (Uchida et al., 1996; Benson and Tanaka, 1998). NCAD expression is modulated by synaptic activity (Shan et al., 2002) and regulates the formation of synapses and dendritic branches in excitatory neurons (Sanes and Yamagata, 1999; Honjo et al., 2000; Togashi et al., 2002; Mendez et al., 2010). Importantly, NCAD coimmunoprecipitates with amyloid precursor protein (Asada-Utsugi et al., 2011) and $A \beta$ decreases the expression of NCAD in cerebral cortical neurons (Ando et al., 2011).

Here we show that neuronal uPA protects the synapse from the harmful effects of soluble $\mathrm{A} \beta$. However, $\mathrm{A} \beta$-induced protein kinase $\mathrm{R}$-like endoplasmic reticulum kinase (PERK)-mediated phosphorylation of eukaryotic initiation factor $2 \alpha$ (eIF2 $\alpha$ ) at serine 51 halts the transcription of uPA mRNA in neurons, leaving unopposed the harmful effect of $\mathrm{A} \beta$ on the synapse. In line with these observations, the synaptic expression of $\mathrm{uPA}$, but not uPA receptor ( $\mathrm{UPAR}$ ), is decreased in the frontal cortex of $\mathrm{AD}$ patients and $5 \mathrm{xFAD}$ mice, and in WT cerebral cortical neurons incubated with soluble $\mathrm{A} \beta$ 1-42 oligomers. This effect is cell type- and organ-specific as is not observed in astrocytes, aorta, or kidneys of $5 \mathrm{xFAD}$ mice, or in WT astrocytes incubated with A $\beta$ 1-42 oligomers. Finally, we found that uPA treatment increases the synaptic expression of NCAD by an uPAR-mediated plasmin-independent mechanism, and that uPA-induced formation of NCAD dimers protects the synapse and dendritic branches from the harmful effects of soluble $\mathrm{A} \beta$ oligomers. Our data indicate that $\mathrm{A} \beta$ induced decrease in the abundance of synaptic uPA contributes to the development of synaptic dysfunction in the early stages of $\mathrm{AD}$, and that uPA treatment is a potential strategy to prevent soluble $\mathrm{A} \beta$-induced synaptic damage before the development of irreversible brain damage.

\section{Materials and Methods}

\section{Animals, human tissue, and reagents}

Animal strains were WT and uPAR-deficient $\left(\mathrm{uPAR}^{-1-}\right)$ pregnant females, and 5-d-old and 6- to 7-month-old 5xFAD male mice [express human A $\beta$ PP with the Swedish (KM670/671NL), Florida (I716V), and London (V717I) mutations, together with a mutant presenilin 1 (M146L, L286V) under the control of the murine Thy-1 promoter] (Buskila et al., 2013), and their WT littermate controls on a C57BL/6J background. Experiments were approved by the Institutional Animal Care \& Use Committee of Emory University. Human samples of brains with $\mathrm{AD}$ and healthy controls (mean age: $75.3 \pm 14.2$ and $75.5 \pm$ 14.8 years, respectively) were obtained from the Emory Alzheimer's Disease Center and Emory, National Institute of Neurological Disorders and Stroke Neurosciences Core facility. Recombinant murine uPA, its amino terminal fragment (ATF; devoid of proteolytic activity), mouse anti-uPA antibody, and mouse uPA total antigen assay ELISA kit were purchased from Molecular Innovations. Other materials were A $\beta$ 1-42 oligomers (rPeptide), the PERK inhibitor GSK 2606414, and BAPTAAM (Tocris Bioscience), the N-cadherin inhibitor Exherin (ADH1; AdooQ Bioscience), phalloidin Alexa-488, the nuclear staining Hoechst, glycine, $\mathrm{KCl}$, and mouse $\mathrm{A} \beta \quad 1-40$ and $\mathrm{A} \beta$ 1-42 ELISA kit (Thermo Fisher Scientific), AM1-44 and advasep-7 (Biotium), trypsin, glutamate, and bicuculline (Sigma Millipore), pepsin (GeneTex), the Apop Tag Plus Fluorescein In Situ Apoptosis Detection Kit (EMD Millipore), and antibodies against A $\beta$ 1-42 (clone 6E10, BioLegend), rabbit PSD-95, rabbit eIF2 $\alpha$ phosphorylated at serine 51 (peIF2 $\alpha$, Cell Signaling Technology), mouse PSD-95 and mouse bassoon (Enzon), rabbit $\mathrm{N}$-cadherin (Abcam), mouse uPA (Santa Cruz Biotechnology), mouse uPAR (R\&D Systems), rabbit uPA (Molecular Innovations), rabbit syntaxin I (STX-I; Millipore), microtubule-associated protein-2, and $\beta$-actin (Sigma Millipore). Secondary antibodies were IRDye $800 \mathrm{CW}$ donkey anti-goat, IRDye $800 \mathrm{CW}$ donkey anti-rabbit, IRDye $800 \mathrm{CW}$ donkey anti-mouse, IRDye 680RD donkey anti-mouse, and IRDye 680RD donkey anti-rabbit (LI-COR); and anti-rabbit Alexa-488, anti-mouse Alexa-488, anti-rabbit Alexa-594, and anti-mouse Alexa-594 (Thermo Fisher Scientific).

\section{Neuronal and astrocytic cultures}

Cerebral cortical neurons and astrocytes were cultured as described previously (Echeverry et al., 2010), from EXVIII 5xFAD and $\mathrm{uPAR}^{-1-}$ mice (neurons), and 5-d-old 5xFAD mice (astrocytes), and from their WT littermate controls. Briefly, the cerebral cortex was dissected, transferred into Hanks balanced salt solution containing 100 units $/ \mathrm{ml}$ penicillin, $100 \mu \mathrm{g} / \mathrm{ml}$ streptomycin, and $10 \mathrm{~mm}$ HEPES, and incubated in trypsin containing $0.02 \% \mathrm{DNase}$ at $37^{\circ} \mathrm{C}$ for $15 \mathrm{~min}$. Tissue was triturated, and the supernatant was resuspended in GS21-supplemented neurobasal medium containing $2 \mathrm{~mm}$ L-glutamine and plated onto $0.1 \mathrm{mg} / \mathrm{ml}$ poly-L-lysine-coated wells. For astrocytes, the triturated tissue was resuspended in $10 \%$ FBS DMEM and filtered through a $70 \mu \mathrm{m}$ pore membrane. Then cells were plated onto poly-l-lysine-coated T75 flasks. Astrocytes were plated and used for experiments on confluency.

\section{Preparation of synaptoneurosomes and Triton-soluble and -insoluble fractions}

Neuronal cultures or cerebral cortices were homogenized and centrifuged at $2000 \times g$ for $5 \mathrm{~min}$ in fractionation buffer containing $1 \mathrm{~mm}$ EGTA, 0.25 M sucrose, and $25 \mathrm{~mm}$ HEPES, pH 8.1. Then, supernatants were centrifuged at $32,000 \times g$ for $10 \mathrm{~min}$. The pellet was resuspended and layered on top of a 5\%-10\% discontinuous Ficoll gradient (Thermo Fisher Scientific) and centrifuged at 50,000 $\times g$ for $20 \mathrm{~min}$ using a Beckman Optima TLX tabletop ultracentrifuge. Synaptoneurosomes were collected from the 5\%-10\% interface and centrifuged at 50,000 $\times g$ for $10 \mathrm{~min}$ at $4^{\circ} \mathrm{C}$. To isolate the Triton-soluble and -insoluble fractions, synaptoneurosomes were prepared from uPA- and vehicle (control)treated cerebral cortices, as described above but without EGTA ( $n=4$ or 5), subjected to osmotic lysis in $10 \mathrm{~mm}$ HEPES and protease inhibitors, and centrifuged at 50,000 $\times g$ during $30 \mathrm{~min}$. The pellet was resuspended in $0.5 \%$ Triton, homogenized, and centrifuged at $40,000 \times g$ during $30 \mathrm{~min}$. The pellet (Triton-insoluble fraction) and supernatant (Triton- 
soluble fraction) were mixed with $1 \%$ SDS prepared and loaded on a gel as described below.

\section{Measurement of the release of neuronal UPA and the concentration of $A \beta$ 1-40 and $A \beta$ 1-42 in the cerebral cortex}

WT cerebral cortical neurons plated on 24 wells were washed and incubated with $300 \mu \mathrm{l}$ of fresh neurobasal medium containing $1 \mu \mathrm{l} / \mathrm{ml}$ DMSO, $200 \mu \mathrm{m}$ glycine, and $20 \mu \mathrm{m}$ bicuculline, followed by $1 \mathrm{~min}$ of treatment with either PBS or $10 \mu \mathrm{m}$ glutamate. A subgroup of cells was preincubated during $30 \mathrm{~min}$ with $30 \mu \mathrm{m}$ of BAPTA-AM before the addition of glutamate ( $n=19$ per condition). After 1 min of treatment, $100 \mu \mathrm{l}$ of media was collected, and the concentration of uPA was measured with an ELISA kit following the manufacturer's instructions (Molecular Innovations). To quantify the concentration of $\mathrm{A} \beta \quad 1-40$ and $\mathrm{A} \beta \quad 1-42$ in the cerebral cortex, we used an ELISA kit (Thermo Fisher Scientific) following the manufacturer's instructions. Briefly, $100 \mathrm{mg}$ of the frontal cortex of 5-d-old 5xFAD mice and their WT littermate controls $(n=3$ per strain) were homogenized in $800 \mu \mathrm{l}$ of $5 \mathrm{M}$ guanidine- $\mathrm{HCl} / 50 \mathrm{~mm}$ Tris, $\mathrm{pH} 8$, mixed at room temperature for $3 \mathrm{~h}$, diluted 10 -fold with cold PBS plus a cocktail of protease inhibitors (Sigma Millipore), and centrifuged at $16,000 \times g$ for $20 \mathrm{~min}$ at $4^{\circ} \mathrm{C}$. The supernatant was diluted twice with a kit dilution buffer, and $100 \mu \mathrm{l}$ of samples or standards was incubated for $2 \mathrm{~h}$ in the antibody-coated plate. Wells were then washed 4 times, and incubated with the kit detector antibody for $1 \mathrm{~h}$ at room temperature. Then, after the plate was washed and incubated with anti-IgG HRP for $30 \mathrm{~min}$ at room temperature, $100 \mu$ lof the kit chromogen buffer was added during $30 \mathrm{~min}$. The absorbance was read at $450 \mathrm{~nm}$. Protein concentration was measured for each sample (Pierce BCA Protein Assay, Thermo Fisher Scientific), and values were expressed as pg of $\mathrm{A} \beta 1-40$ or $\mathrm{A} \beta 1-42 / \mathrm{mg}$ of protein.

\section{Preparation of $A \beta$ 1-42 oligomers}

A $\beta$ 1-42 oligomers were prepared as previously described (Fa et al., 2010). Briefly, $80 \mu \mathrm{m} \mathrm{A} \beta$ 1-42 monomers were lyophilized in 1,1,1,3,3,3hexafluoro-2-propanol, resuspended in DMSO to a $5 \mathrm{~mm}$ concentration, and incubated in PBS overnight. Experiments were performed with doses to reach a final concentration of $100 \mathrm{~nm}$ of $\mathrm{A} \beta$ 1-42 oligomers.

\section{Electrophysiology}

To study the effect of uPA on A $\beta$-induced synaptic dysfunction, we performed patch-clamp recordings to examine sEPSCs on DIV14-DIV17 WT cerebral cortical neurons incubated during $24 \mathrm{~h}$ with $\mathrm{A} \beta$ oligomers, alone or in the presence of uPA (given in three doses of a 5 nM solution immediately after the addition of $\mathrm{A} \beta$, and 12 and $23 \mathrm{~h}$ later). Coverslips containing cells were transferred to a recording chamber and perfused at $0.2 \mathrm{ml} / \mathrm{min}$ with a Ringer's solution ( $\mathrm{pH} 7.4,300 \mathrm{mOsm}$ ) containing the following (in mM): $145 \mathrm{NaCl}, 3 \mathrm{KCl}, 1.5 \mathrm{CaCl}_{2}, 1 \mathrm{MgCl}_{2}, 10 \mathrm{HEPES}$, and 10 glucose. Individual neurons were visually identified under polarized illumination using an STP 6000 microscope (Leica Microsystems), and pyramidal neurons were chosen based on their soma shape and membrane properties. Whole-cell patch-clamp recordings were performed using a MultiClamp 700B amplifier, Digidata 1550 digitizer, and pClamp 10.6 software (Molecular Devices). Recording pipettes with a resistance of 4-6 M $\Omega$ were pulled from borosilicate glass using a Sutter P-

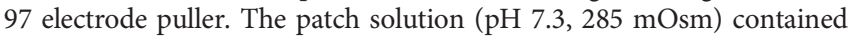
the following (in $\mathrm{mM}$ ): $130 \mathrm{~K}$-gluconate, $2 \mathrm{KCl}, 10 \mathrm{HEPES}, 3 \mathrm{MgCl}_{2}, 5$ phosphocreatine, $2 \mathrm{~K}-\mathrm{ATP}$, and $0.2 \mathrm{NaGTP}$. Access resistances measured in voltage clamp were in the range of 15-30 $\mathrm{M} \Omega$. Whole-cell currents were filtered at $3 \mathrm{kHz}$ and digitized at $10 \mathrm{kHz}$. Spontaneous Excitatory Postsynaptic Currents (sEPSCs) were recorded at holding potential of $-60 \mathrm{mV}$. All sEPSCs were detected offline using the MiniAnalysis program 6.0 (Synaptosoft). We examined four neurons in each quadrant of each coverslip, for a total of 17-24 neurons from 5 different cultures. The investigator performing the patch-clamp recordings remained blind to the experimental conditions and their statistical analysis.

\section{Western blot analyses}

To study the expression of UPA, uPAR, and STX-I in the cerebral cortex, whole extracts were prepared from the frontal cortex of WT mice $(n=4)$, DIV16 WT cerebral cortical neurons $(n=4), 5$-d-old astrocytes cultured from the cerebral cortex of 5xFAD mice and their WT littermate controls $(n=8)$, and the aorta and kidney dissected from $5 x F A D$ mice $(n=4)$ and their WT littermate controls $(n=4)$. To study the expression of uPA in the synapse, synaptoneurosomes were prepared from the frontal cortex of 6-month-old $(n=4)$ and 5-d-old 5xFAD mice and their WT littermate controls $(n=4)$, DIV16 WT cerebral cortical neurons, and the frontal cortex of $\mathrm{AD}$ patients and healthy controls ( $n=6$ per group). To study the purity of the $\mathrm{A} \beta$ 1-42 oligomers used for our in vitro studies, $108 \mu \mathrm{g}$ of $\mathrm{A} \beta$ 1-42 oligomers was left untreated or incubated with PBS overnight. To study the effect of $\mathrm{A} \beta$ on the expression of uPA, $100 \mathrm{~nm}$ of A $\beta$ 1-42 oligomers was added during $0-24 \mathrm{~h}$ to DIV16 WT cerebral cortical neurons and WT astrocytes $(n=4)$. To determine whether eIF $2 \alpha$ mediates the effect of $\mathrm{A} \beta$ on uPA expression, DIV16 WT cerebral cortical neurons were incubated 0,1 , or $24 \mathrm{~h}$ with $100 \mathrm{~nm}$ of $\mathrm{A} \beta 1-42$ oligomers, alone or in combination with $1 \mu \mathrm{m}$ of the PERK inhibitor GSK $2606414(n=5)$. To study the effect of uPA on NCAD expression and to determine whether it requires uPA's proteolytic activity, synaptoneurosomes were prepared from WT cerebral cortical neurons incubated $30 \mathrm{~min}$ with vehicle control or $5 \mathrm{~nm}$ of either uPA or its ATF. To investigate the effect of uPA on trypsin-induced cleavage of NCAD monomers, whole-cell extracts were prepared from WT cerebral cortical neurons incubated during $30 \mathrm{~min}$ with vehicle (control) and $5 \mathrm{~nm}$ of either uPA or its ATF, and then treated $10 \mathrm{~min}$ with EDTA-free $0.006 \%$ trypsin $(n=6)$. To investigate the effect of uPA on the formation of NCAD dimers, Triton-soluble and -insoluble fractions were isolated from synaptoneurosomes prepared from the frontal cortex of WT mice treated during $30 \mathrm{~min}$ with $5 \mathrm{nM}$ of uPA or vehicle (control; $n=5$ ). To study the effect of $\mathrm{A} \beta$ on NCAD expression, whole-cell extracts were prepared from WT cerebral cortical neurons incubated $24 \mathrm{~h}$ with $100 \mathrm{~nm}$ of $\mathrm{A} \beta$ 1-42 oligomers, alone or in the presence of three doses of $5 \mathrm{~nm}$ of either uPA or its ATF administered at the beginning of the experiment, and 12 and $23 \mathrm{~h}$ later ( $n=4$ per time point). Proteins were quantified with the BCA assay, and equal amounts were loaded and separated onto a $4 \%-15 \%$ SDS-gel, transferred into a nitrocellulose membrane, blocked with LI-COR blocking buffer, and incubated overnight at $4{ }^{\circ} \mathrm{C}$ with antibodies against mouse uPA (1:1000), STX-I (1:2000), actin (1:50,000), rabbit $\mathrm{N}$-cadherin (1:2000), goat uPAR (1:1000), rabbit peIF2 $\alpha$ (1:1000), and $\mathrm{A} \beta$ 1-42 (1:1000). Then membranes were washed and incubated during $1 \mathrm{~h}$ with IRDye $800 \mathrm{CW}$ donkey anti-rabbit $(1: 10,000)$, IRDye $800 \mathrm{CW}$ donkey anti-goat $(1: 10,000)$, IRDye $800 \mathrm{CW}$ donkey anti-mouse $(1: 10,000)$, IRDye 680RD donkey anti-mouse $(1: 10,000)$, and IRDye 680RD donkey anti-rabbit antibodies $(1: 10,000)$. Membranes were developed using a LI-COR Odyssey Fc reader. Quantifications were performed using the Image Studio software. Values were expressed as a ratio of intensity of the band/actin intensity and normalized to each control.

\section{Immunohistochemistry}

To study the expression of uPA and NCAD in the cerebral cortex, $30 \mu \mathrm{m}$ sections were obtained from the frontal cortex of $5 \mathrm{xFAD}$ mice $(n=6)$ and their WT littermate controls $(n=7)$, and from $\mathrm{AD}$ patients and healthy controls $(n=5)$. To study the effect of $\mathrm{A} \beta$ on uPA and uPAR expression, WT cerebral cortical neurons were incubated $24 \mathrm{~h}$ with 100 nм of A $\beta$ 1-42 monomers, alone or in combination with $5 \mathrm{~nm}$ of uPA or its ATF, administered at the beginning of the experiment, and 12 and 23 $\mathrm{h}$ thereafter. To study the effect of uPA on the formation of synaptic contacts, DIV16 WT cerebral cortical neurons were incubated $30 \mathrm{~min}$ with vehicle (control) or $5 \mathrm{nM}$ of uPA, alone or in combination with 175 $\mu \mathrm{M}$ of ADH1 (NCAD inhibitor). To study the effect of uPA on NCAD expression, murine WT and $\mathrm{uPAR}^{-1-}$ cerebral cortical neurons were incubated with $5 \mathrm{~nm}$ of uPA or a comparable volume of vehicle (control). To study the effect of A $\beta$ on NCAD expression, DIV14-DIV16 WT cerebral cortical neurons were incubated during $24 \mathrm{~h}$ with $100 \mathrm{~nm}$ of $\mathrm{A} \beta$ 142 monomers, alone or in combination with three doses of $5 \mathrm{nM}$ of uPA 

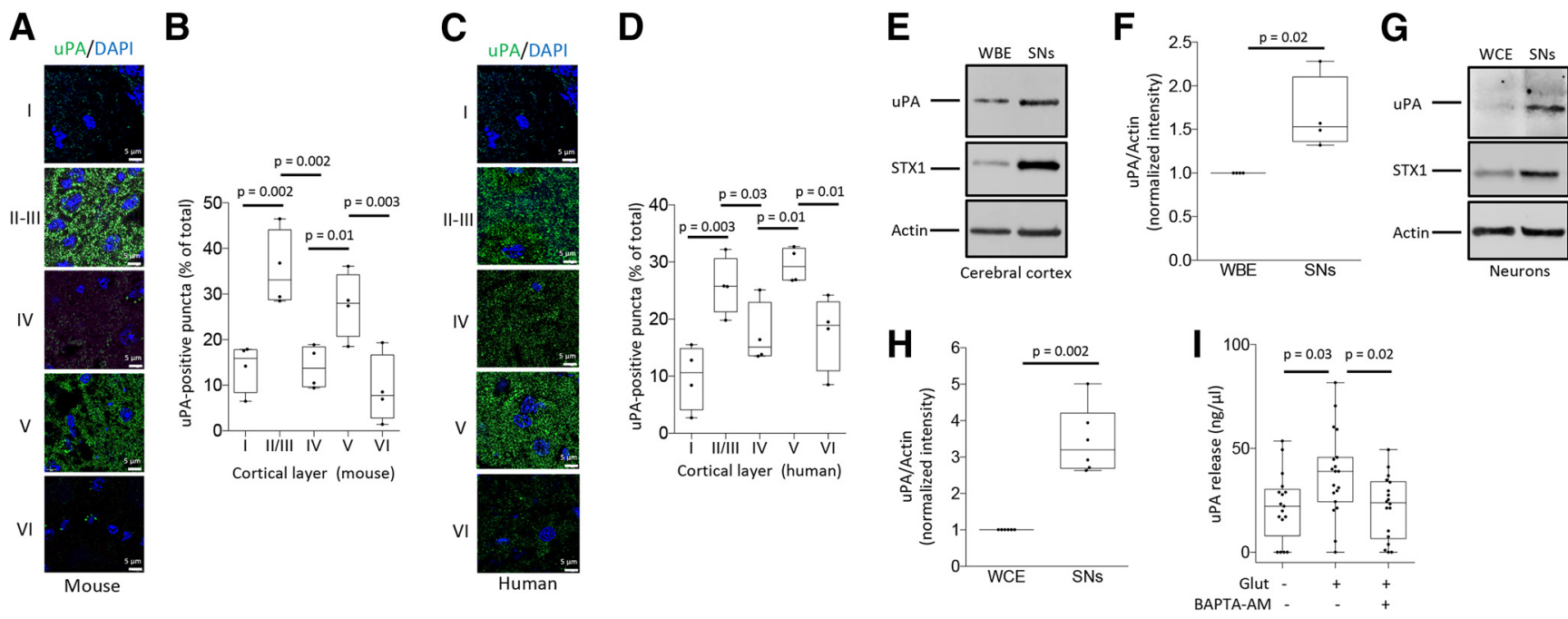

Figure 1. uPA expression in the cerebral cortex. $\boldsymbol{A}-\boldsymbol{D}$, Representative confocal micrographs at $282 \times$ magnification of individual cortical layers from the murine $(\boldsymbol{A})$ and human $(\boldsymbol{C})$ frontal cortex immunostained with anti-uPA antibodies (green) and Hoechst (blue). $\boldsymbol{B}, \boldsymbol{D}$, The percentage of uPA-positive puncta in each cortical layer in relation to the total number of puncta in the six cortical layers ( $n=20$ pictures per layer from 4 mice and human brains). $\boldsymbol{B}, \boldsymbol{D}$, Statistical analysis: one-way ANOVA with Holm-Sidak's multiple comparisons test. $\boldsymbol{E}$-H, Representative Western blot analysis $(\boldsymbol{E}, \boldsymbol{G})$ and quantification of the normalized intensity of the band $(\boldsymbol{F}, \boldsymbol{H})$ of uPA expression in whole extracts and synaptoneurosomes prepared from either the frontal cortex $(\boldsymbol{E}, \boldsymbol{F})$ or WT cerebral cortical neurons $(\mathbf{G}, \boldsymbol{H}) . n=4$ observations per experimental group. Statistical analysis: two-tailed Student's $t$ test. $\boldsymbol{I}$, Mean concentration of uPA in the culture medium of WT cerebral cortical neurons incubated during $60 \mathrm{~s}$ with vehicle (control), or a combination of $10 \mu \mathrm{m}$ of glutamate, $20 \mu \mathrm{m}$ bicuculline, and $200 \mu \mathrm{m}$ glycine, alone or in the presence of $30 \mu \mathrm{m}$ of BAPTA-AM. $n=19$ observations per condition. One-way ANOVA with Tukey's multiple comparisons test.

administered at the beginning of the experiment and 12 and $23 \mathrm{~h}$ later. A subset of samples was treated with only one dose of uPA $24 \mathrm{~h}$ after the addition of $\mathrm{A} \beta$. Brain slices were permeabilized with $0.1 \%$ Triton, blocked with 3\% BSA in TBS during $1 \mathrm{~h}$, and incubated overnight with antibodies against murine uPA (1:100), or N-cadherin (1:400). Samples were then washed and incubated with Hoechst (1:5000) and either antimouse Alexa-488 (1:500) or anti-rabbit Alexa-488 (1:500) secondary antibodies. Pictures were taken from the frontal cortex at a $40 \times$ magnification with an immunofluorescent microscope (Olympus IX83), and from each cortical layer at $283 \times$ magnification with a Fluoview FV10i automated confocal laser-scanning microscope (Olympus). Quantification of uPA- and NCAD-positive puncta was performed in confocal micrographs taken from individual cortical layers at $282 \times$ magnification. Values are given as percentage of the total number of uPA-positive puncta in the six cortical layers, or as a mean number of uPA/positive puncta/2025 $\mu^{2}$. Images were processed with ImageJ and the plugin puncta analyzer. Cells were fixed in 4\% PFA $24 \mathrm{~h}$ after the addition of $\mathrm{A} \beta$, permeabilized with $0.1 \%$ Triton, blocked with $3 \%$ BSA in TBS during $20 \mathrm{~min}$, and incubated overnight with antibodies against either murine uPA (1:100), or murine uPAR (1:400), murine bassoon (1:100), STX-I (1:400), and rabbit PSD-95 (1:100). Then, cells were washed and incubated with Hoechst (1:5000) and a 1:500 dilution of the following secondary antibodies: anti-mouse Alexa-594, anti-rabbit Alexa-594, anti-goat Alexa-488, or anti-mouse Alexa-488. Confocal micrographs were taken at $60 \times$ and deconvoluted using 64 iterations of the CellSens dimension 1.17 software (Olympus). Quantifications were performed using the ImageJ and the plugin puncta analyzer.

\section{Quantification of dendritic branches}

To study the effect of uPA on the complexity of the dendritic tree, DIV14 WT cerebral cortical neurons were incubated with $175 \mu \mathrm{M}$ of $\mathrm{ADH} 1$ or a comparable volume of vehicle (control) $30 \mathrm{~min}$ before the addition of $5 \mathrm{~nm}$ of uPA or vehicle (control). To study the effect of uPA on the harmful effect of $A \beta$ on dendritic branches, DIV14 WT cerebral cortical neurons were incubated during $24 \mathrm{~h}$ with vehicle (control) or $100 \mathrm{~nm}$ of A $\beta$ 1-42 oligomers, alone or in the presence of three doses of $5 \mathrm{~nm}$ of uPA added at the beginning of the experiment, and 12 and $23 \mathrm{~h}$ later, alone or in combination with $175 \mathrm{~nm}$ of ADH1 or vehicle (control). At $30 \mathrm{~min}$ after the addition of uPA for the first group of experiments, and $60 \mathrm{~min}$ after the last dose of uPA for the second set of experiments
( $24 \mathrm{~h}$ after the addition of $\mathrm{A} \beta$ ), neurons were fixed with $4 \%$ PFA and incubated $15 \mathrm{~min}$ with $0.1 \%$ Triton and blocked during $30 \mathrm{~min}$ with BSA $3 \%$, followed by staining with phalloidin-488 (1:1000) and anti-microtubule-associated protein-2 antibodies (1:2500). The number of dendritic intersections $0-70 \mu \mathrm{m}$ away from the soma was quantified in pictures taken at $20 \times$ magnification using the Sholl analysis plugin of Image J.

\section{Quantification of AM1-44 uptake}

WT cerebral cortical neurons were incubated during $24 \mathrm{~h}$ with vehicle (control) or $100 \mathrm{~nm}$ of $\mathrm{A} \beta \quad 1-42$ oligomers, alone or in the presence of three doses of $5 \mathrm{nM}$ of uPA added at the beginning of the experiment, and 12 and $23 \mathrm{~h}$ later. Twenty-four hours after the last dose of uPA, cells were incubated during 2 min with Tyrode's buffer containing $125 \mathrm{mM}$ $\mathrm{NaCl}, 2 \mathrm{~mm} \mathrm{KCl}, 2 \mathrm{~mm} \mathrm{CaCl}$, 2 mм MgCl 2,25 mм HEPES, $30 \mathrm{~mm}$ Dglucose, $5 \mu \mathrm{M}$ of AM1-44, and $45 \mathrm{~mm}$ of $\mathrm{KCl}$. Cells were then washed; and $5 \mathrm{~min}$ later, $5 \mu \mathrm{m}$ of ADVASEP-7 was added to reduce background and induce the release of membrane-bound AM1-44. Five minutes later, cells were treated with $45 \mathrm{nM}$ of $\mathrm{KCl}$ to induce the release of AM1-44 incorporated into synaptic vesicles. Quantifications were made in images taken with an Olympus microscope IX83 and a DP80 camera at a 20× magnification.

\section{Quantification of neuronal survival}

The effect of $A \beta$ on neuronal survival was studied by quantifying the uptake of propidium iodide and the number of TUNEL-positive cells in WT cerebral cortical neurons incubated during $24 \mathrm{~h}$ with vehicle (control) or 100 nм of A $\beta$ 1-42 oligomers. As a control, cell death was induced in a third group of cells with $50 \mu \mathrm{M}$ of glutamate. Quantifications were automatically performed with the CellSens dimension 1.17 software (Olympus).

\section{Quantitative PCR analysis}

Total RNA was extracted using a RNeasy mini kit from QIAGEN from WT cerebral cortical neurons incubated 0,1 , and $24 \mathrm{~h}$ with $100 \mathrm{~nm}$ of A $\beta$ 1-42 oligomers $(n=8)$ followed by cDNA synthesis with a RNAiScript cDNA Synthesis kit purchased from Bio-Rad. Then, uPA mRNA was quantified with a QuantStudio 3 thermocycler (Thermo Fisher Scientific) using TaqMan fast advanced master mix (Thermo Fisher Scientific) in combination with Plau FAM-MGB (Mm00447054_m1, Thermo Fisher Scientific) or GAPDH FAM-MGB 
A

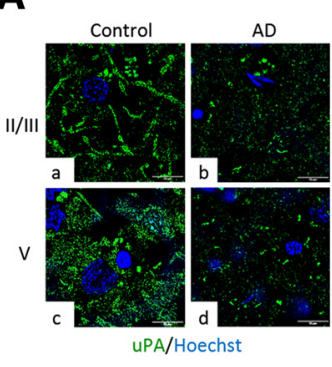

E

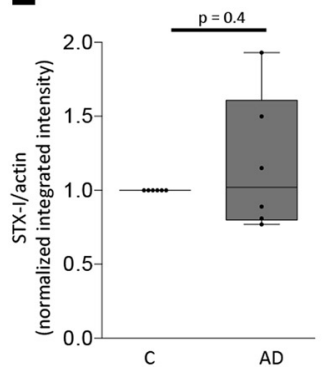

B

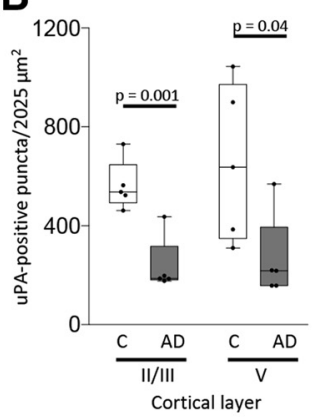

$\mathbf{F}$

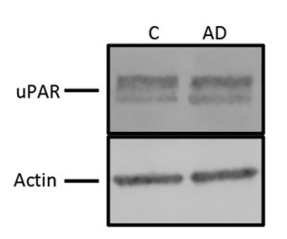

G
C
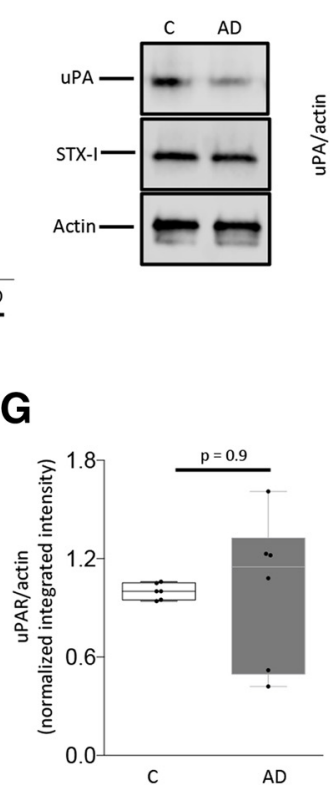

D

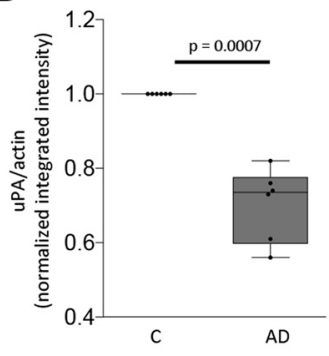

Figure 2. Effect of AD on uPA and uPAR expression. $\boldsymbol{A}, \boldsymbol{B}$, Representative confocal micrographs at $282 \times$ magnification from sections taken from the II/III and V frontal cortical layers of a brain with $\mathrm{AD}(\boldsymbol{A} \boldsymbol{b}, \boldsymbol{A d})$ and a healthy control $(\boldsymbol{A} \boldsymbol{a}$ and $\boldsymbol{A} \boldsymbol{c})$ and a brain with $\mathrm{AD}(\boldsymbol{A} \boldsymbol{b}$ and $\boldsymbol{A d})$. $\boldsymbol{B}$, The mean number of uPA-positive puncta in the II/III and $\mathrm{V}$ cortical layers in both experimental groups. $n=5$ brains per group and 5 pictures per brain. Statistical analysis: two-tailed Student's $t$ test. $\boldsymbol{C}-\boldsymbol{G}$, Representative Western blot analyses $(\boldsymbol{C}, \boldsymbol{F})$ and quantification of the mean intensity of the band $(\boldsymbol{D}, \boldsymbol{E}, \boldsymbol{G})$ of uPA and STX-I $(\boldsymbol{C}-\boldsymbol{E})$ and UPAR $(\boldsymbol{F}, \boldsymbol{G})$ in synaptoneurosomes prepared from the frontal cortex of AD patients and healthy control brains. $n=6$ brains per experimental condition. $\boldsymbol{D}, \boldsymbol{E}, \boldsymbol{G}$, Statistical analysis: two-tailed Student's $t$ test.

(Mm99999915_g1, Thermo Fisher Scientific). Values are expressed as mean values obtained from $\Delta \Delta \mathrm{C}_{\mathrm{t}}$ using GAPDH as internal control.

\section{Statistics}

Statistical analysis was performed with Student's $t$ test and one- or twoway ANOVA with corrections, as deemed appropriate and described in each figure legend. $p$ values of $<0.05$ were considered as significant.

\section{Results}

uPA expression in the cerebral cortex

First, we used confocal microscopy to study the expression of uPA in the frontal cortex of the murine brain. We found that, although uPA-positive puncta are detected throughout the entire cortex, most of them are located in the II/III and V cortical layers $(35.30 \pm 8.34 \%$ and $27.65 \pm 3.6 \%$ of the total number of uPApositive puncta in the six cortical layers, respectively; Fig. $1 A, B$; $n=4$ mice). These observations were replicated in the frontal cortex of the healthy human brain, in which most of uPA-positive puncta were also detected in the II/III and V cortical layers $(26 \% \pm 2.53 \%$ and $29 \pm 1.5 \%$ of the total number of uPA-positive puncta in the six cortical layers; Fig. $1 C, D ; n=4$ brains). Furthermore, our studies with whole-brain extracts and synaptoneurosomes (assembled by the sealed axonal bouton and attached postsynaptic terminal) prepared from the frontal cortex of WT mice and DIV17 WT cerebral cortical neurons indicate that most of this uPA is localized in the synapse (Fig. 1E-H). Additionally, we found that $60 \mathrm{~s}$ of incubation with a combination of glutamate, bicuculline, and glycine [to increase synaptic activity without causing cell death (Jeanneret et al., 2018)] triggers its release via a calcium-dependent mechanism (Fig. 1I).

\section{Effect of AD on the synaptic expression of UPA and UPAR} Several studies have reported variations in uPA gene (Ozturk et al., 2007) and uPA protein (Whelan et al., 2019) in AD patients.
Thus, we decided to use confocal microscopy to study its expression in brain sections obtained from the frontal cortex of $\mathrm{AD}$ patients and healthy controls ( $n=4$ brains per group). Our data indicate that, compared with controls, the expression of uPA is decreased in the II/III and V cortical layers of AD brains (Fig. 2A,B). Additionally, our studies with synaptoneurosomes show that the synaptic abundance of uPA is decreased in the frontal cortex of these patients (Fig. 2C,D). Importantly, probing of these membranes with antibodies against STX-I shows that equal amounts of synaptic extracts were loaded in both experimental groups (Fig. 2C,E). Remarkably, in contrast with the expression of $\mathrm{UPA}$, we did not find a reduction in the abundance of its receptor ( $\mathrm{UPAR}$ ) in the synapse of $\mathrm{AD}$ brains (Fig. 2F,G).

We then performed similar observations in the frontal cortex of 6- to 7-month-old 5xFAD mice and their WT littermate controls. We found that, as observed in AD patients, the expression of uPA is decreased in the II/III and V cortical layers of 5XFAD mice (Fig. 3A,B). Moreover, studies with synaptoneurosomes revealed that the synaptic abundance of uPA (Fig. $3 C-E$ ), but not uPAR (Fig. 3F,G), is decreased in the frontal cortex of these animals. Importantly, the observed decrease in uPA expression in $5 x F A D$ mice was specific to the brain, as it was not observed in their aorta (Fig. $3 H, I$ ) or kidneys (Fig. 3J,K). To determine whether this effect is cell-type-specific, we studied the expression of uPA in astrocytes prepared from the frontal cortex of 5-d-old $5 x F A D$ mice and their WT littermate controls. To control for the young age of the animals used to prepare these cultures, we performed similar observations with synaptoneurosomes isolated from the frontal cortex of $5 x F A D$ mice and their WT littermate controls of comparable age. We found that the expression of uPA is decreased in the synapse (Fig. $3 L-N$ ), but not in astrocytes (Fig. 3O,P), of 5xFAD mice. Importantly, some extracts prepared from 5XFAD astrocytes exhibited increased GFAP immuno- 
A

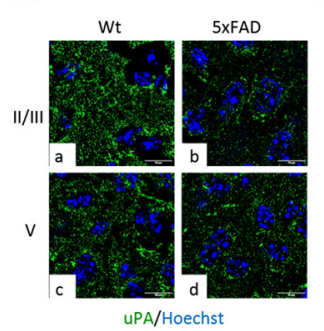

G

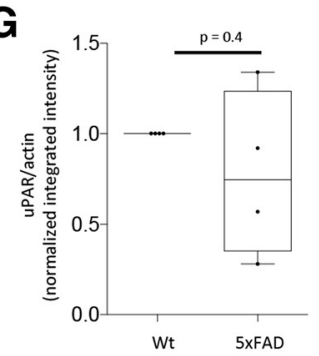

M

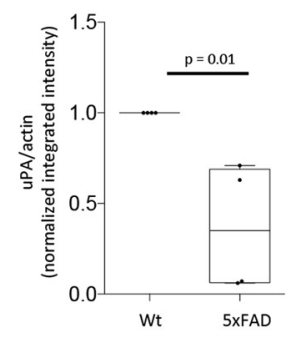

B
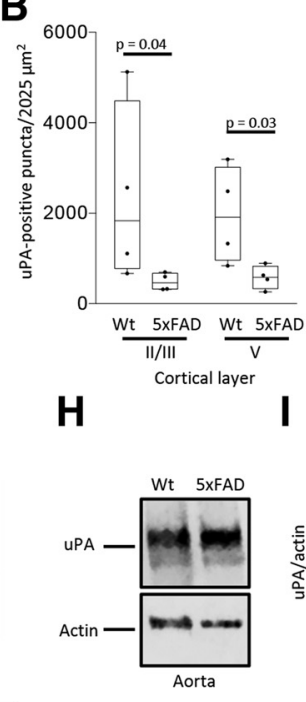

N

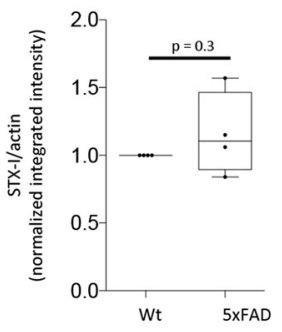

C

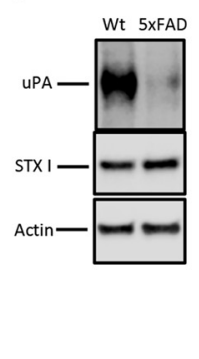

D

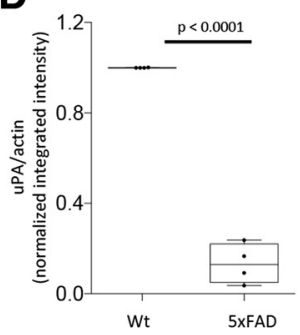

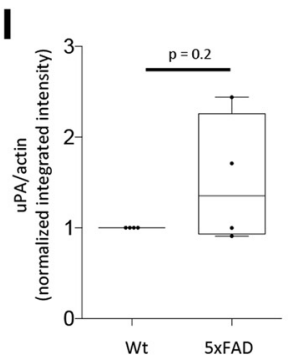

J

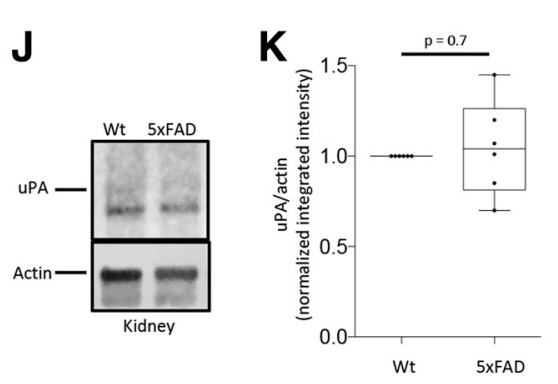

E

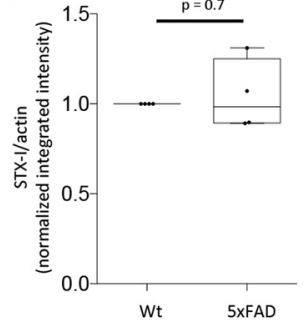

F

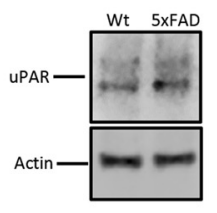

L

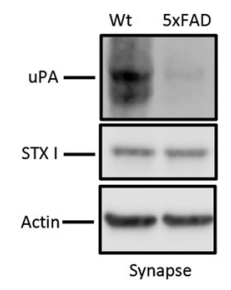

Figure 3. UPA and uPAR expression in $5 \mathrm{xFAD}$ mice. $\boldsymbol{A}, \boldsymbol{B}$, Representative confocal micrographs at $282 \times$ magnification from sections taken from the II/III and $\mathrm{V}$ cortical layers from the frontal cortex of 5xFAD mice $(\boldsymbol{A b}, \boldsymbol{A d})$ and their WT littermate controls $(\boldsymbol{A} \boldsymbol{a}, \boldsymbol{A c})$. $\boldsymbol{B}$, The mean number of uPA-positive puncta in the II/III and $\mathrm{V}$ cortical layers in both experimental groups. $n=7$ brains per group and 5 pictures per brain. Statistical analysis: two-tailed Student's $t$ test. $\boldsymbol{C}-\boldsymbol{G}$, Representative Western blot analyses $(\boldsymbol{C}, \boldsymbol{F})$ and quantification of the mean intensity of the band of uPA $(\boldsymbol{D})$, STX-I $(\boldsymbol{E})$, and UPAR $(\boldsymbol{G})$ expression in synaptoneurosomes prepared from the frontal cortex of 6-month-old 5xFAD mice and their WT littermate controls. $n=4$ animals per experimental conditions. Statistical analysis: two-tailed Student's $\boldsymbol{t}$ test. $\boldsymbol{H}-\boldsymbol{K}$, Representative Western blot analyses $(\boldsymbol{H}, \boldsymbol{J})$ and quantification of the mean intensity of the band $(\boldsymbol{I}, \boldsymbol{K})$ of uPA expression in the aorta $(\boldsymbol{H}, \boldsymbol{I})$ and kidneys $(\boldsymbol{J}, \boldsymbol{K})$ of $5 x$ FAD mice and their WT littermate controls. $n$ per experimental condition: $\boldsymbol{I}, 4$ mice; $\boldsymbol{K}, 6$ mice. Statistical analysis: two-tailed Student's $t$ test. $\boldsymbol{L}-\boldsymbol{P}$, Representative Western blot analyses $(\boldsymbol{L}, \mathbf{0})$ and quantification of the mean intensity of the band $(\boldsymbol{M}, \boldsymbol{N}, \boldsymbol{P})$ of uPA, STX-I, GFAP, and actin expression in extracts from synaptoneurosomes and astrocytes prepared from the frontal cortex of 5-d-old 5XFAD mice and their WT littermate controls. $\boldsymbol{M}, \boldsymbol{N}, n=4$. $\boldsymbol{P}, n=8$. Statistical analysis: two-tailed Student's $t$ test. $\boldsymbol{Q}$, Mean concentration of $A \beta$ 1-40 and $A \beta$ 1-42 in the frontal cortex of 5-d-old 5XFAD mice and their WT littermate controls. $n=6$ samples from 3 different brains per experimental group. Statistical analysis: twotailed Student's $t$ test.

reactivity compared with WT astrocytes, despite equal protein loading in both experimental groups (data not shown). Furthermore, our ELISA experiments indicate that, at that age, the concentrations of $\mathrm{A} \beta \quad 1-40$ and $\mathrm{A} \beta \quad 1-42$ are already increased in the cerebral cortex of these animals (Fig. 3Q).

\section{Effect of $A \beta$ on uPA and uPAR expression}

First, we quantified cell death in WT cerebral cortical neurons incubated with soluble $\mathrm{A} \beta$ 1-42 oligomers prepared as described in Materials and Methods (Fig. 4A). Our propidium iodide (Fig. $4 B$ ) intake and TUNEL assays (Fig. $4 C$ ) indicate that $24 \mathrm{~h}$ of incubation with $100 \mathrm{~nm}$ of soluble $\mathrm{A} \beta$ 1-42 oligomers does not induce cell death. Thus, we used this experimental design to study the effect of $\mathrm{A} \beta$ on $\mathrm{uPA}$ and uPAR expression in cerebral cortical neurons. We found that $\mathrm{A} \beta$ decreases the expression of uPA (Fig. 4D-G), but not uPAR (Fig. 4H-K), in WT cerebral cortical neurons. Importantly, this effect is neuronspecific, as it was not detected in WT astrocytes incubated with $\mathrm{A} \beta$ (Fig. $4 L, M$ ). Furthermore, our data indicate that $\mathrm{A} \beta$ inhibits the translation of uPA mRNA in cerebral cortical neurons, as it decreases the expression of uPA protein (Fig. $5 A, B$ ), but not uPA mRNA (Fig. 5C). Because peIF $2 \alpha$ inhibits mRNA translation in neurons of AD patients (Chang et al., 2002; Hoozemans et al., 2009; Ma et al., 2013), we decided to investigate whether peIF $2 \alpha$ mediates the effect of $\mathrm{A} \beta$ on uPA expression. We found that $\mathrm{A} \beta$ increases the abundance of peIF2 $\alpha$ in cerebral cortical neurons (Fig. $5 D, E$ ) and that inhibition of PERK-induced eIF2 $\alpha$ phosphorylation with GSK 2606414 (Fig. 5F,G) effectively abolishes the deleterious effect of $\mathrm{A} \beta$ on uPA expression (Fig. $5 H, I$ ).

\section{uPA protects the synapse from the harmful effects of $A \beta$}

Several lines of experimental evidence indicate that $\mathrm{A} \beta$ has a deleterious effect on the synapse (Lue et al., 1999; Fitzjohn et al., 2001; Selkoe, 2002). Because our previous studies show that uPA protects the synapse from different forms of injury (Merino et al., 2017; Diaz et al., 2017, 2019), we then studied whether uPA also protects the synapse from the harmful effects of $\mathrm{A} \beta$. Since $\mathrm{A} \beta$ oligomers have a deleterious effect on the presynaptic release of neurotransmitters (He et al., 2019), first we studied the 
A

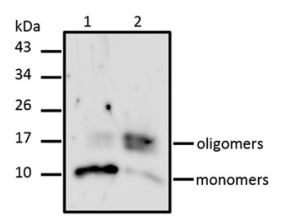

G

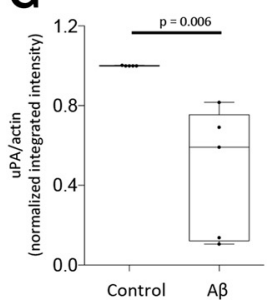

B

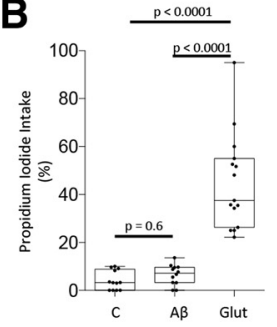

C

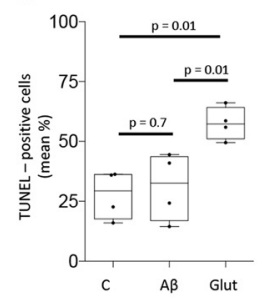

D

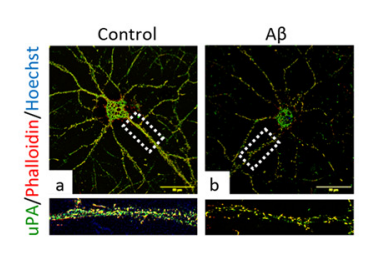

K

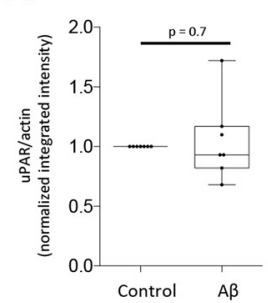

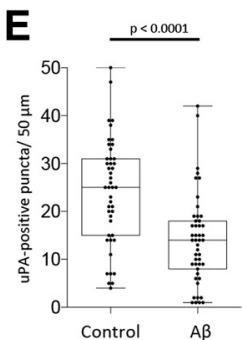

$\mathbf{F}$

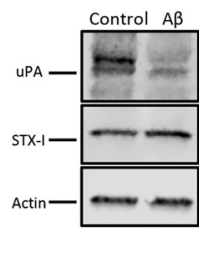

H

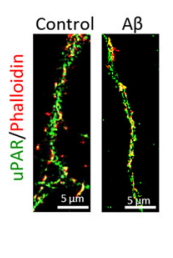

I

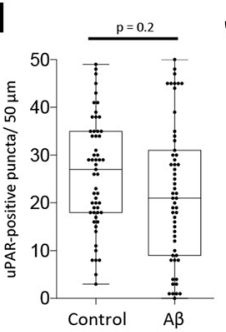

J

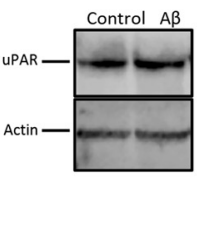

$\mathbf{L}$

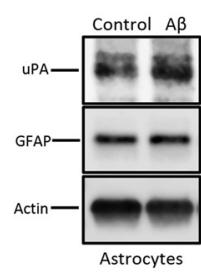

M

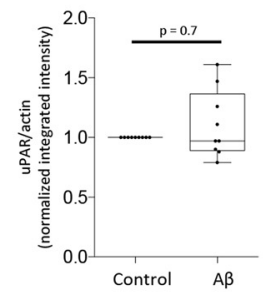

Figure 4. Effect of $A \beta$ on uPA expression. $\boldsymbol{A}$, Representative Western blot analysis of $A \beta$ 1-42 oligomers prepared as described in Materials and Methods and either left untreated (lane 1 , monomers) or incubated overnight with PBS (lane 2, oligomers). B, Mean propidium iodide (PPI) intake by WT cerebral cortical neurons incubated $24 \mathrm{~h}$ with vehicle (control) or $100 \mathrm{~nm}$ of A $\beta$ 1-42 oligomers, or $1 \mathrm{~h}$ with $50 \mu \mathrm{m}$ of glutamate. Each point represents the average number of PPI-positive neurons per picture from neurons from three different cultures [ $n=12$ pictures/444 cells (control), 12 pictures/465 cells (A $\beta$ - treated neurons) and 15 pictures/430 cells (glutamate-treated neurons)]. Statistical analysis: one-way ANOVA with Holm-Sidak's multiple comparisons test. $\boldsymbol{C}$, Mean percentage of TUNEL-positive cells in WT cerebral cortical neurons exposed to the experimental conditions described in $\boldsymbol{B}$. Each point represents the average number of TUNEL-positive cells per culture (4 different cultures). $n=16,713$ cells (control), 10,854 cells (A $\beta$ - treated neurons), and 13,167 cells (glutamate-treated neurons). Statistical analysis: one-way ANOVA with Holm-Sidak's multiple comparisons test. $\boldsymbol{D}, \boldsymbol{E}$, Representative confocal micrographs at $60 \times$ magnification of WT cerebral cortical neurons stained with Hoechst (blue) and antibodies against uPA (green) and phalloidin (red) after $24 \mathrm{~h}$ of incubation with $100 \mathrm{~nm}$ of A $\beta$ 1-42 oligomers or vehicle-control. Bottom panels, $A 4 \times$ electronic magnification of the area denoted by the dashed square in $\boldsymbol{D a}$ and $\boldsymbol{D} \boldsymbol{b}$. $\boldsymbol{C}$, The mean number of uPA-positive puncta/50 $\mu \mathrm{m} . n=48$ extensions per experimental group. Statistical analysis: two-tailed Student's $t$ test. $\boldsymbol{F}$, $\mathbf{G}$, Representative Western blot analysis $(\boldsymbol{F})$ and quantification of the mean intensity of the band $(\boldsymbol{G})$ of uPA expression in synaptoneurosomes prepared from WT cerebral cortical neurons treated during $24 \mathrm{~h}$ with $\mathrm{A} \beta$ 1-42 oligomers or vehicle (control). $n=5$ per experimental group. Statistical analysis: two-tailed Student's $t$ test. $\boldsymbol{H}, \boldsymbol{I}$, Representative confocal micrographs at $100 \times$ magnification of extensions of WT cerebral cortical neurons immunostained with phalloidin and antibodies against uPAR (green) after $24 \mathrm{~h}$ of incubation with $\mathrm{A} \beta$ or vehicle (control). $I$, The mean number of uPA-positive puncta/50 $\mu \mathrm{m}$ in 60 extensions of WT neurons exposed to the experimental conditions described in $\boldsymbol{H}$. Statistical analysis: two-tailed Student's $t$ test. $\boldsymbol{J}$ - $\boldsymbol{M}$, Representative Western blot analyses $(\boldsymbol{J}, \boldsymbol{L})$ and quantification of the mean intensity of the band $(\boldsymbol{K}, \boldsymbol{M})$ of uPAR $(\boldsymbol{J}, \boldsymbol{K})$ and uPA and GFAP $(\boldsymbol{L}, \boldsymbol{M})$ expression in WT cerebral cortical neurons $(\boldsymbol{J}, \boldsymbol{K})$ and astrocytes $(\boldsymbol{L}, \boldsymbol{M})$ incubated $24 \mathrm{~h}$ with $\mathrm{A} \beta$ or vehicle (control).

activity-dependent uptake of the fluorescent nerve terminal probe AM1-44 by presynaptic vesicles of WT cerebral cortical neurons depolarized with $50 \mu \mathrm{M}$ of $\mathrm{KCl}$ after $24 \mathrm{~h}$ of incubation with $100 \mathrm{~nm}$ of soluble $\mathrm{A} \beta$ 1-42 oligomers or vehicle (control), alone or in the presence of $5 \mathrm{~nm}$ of uPA. Our studies reveal that $\mathrm{A} \beta$ has a harmful effect on presynaptic function (denoted by a decrease in the uptake of AM1-44) that is attenuated by uPA treatment (Fig. 6A,B). We then used the same experimental design and confocal microscopy to quantify the number of bassoon/PSD-95-positive puncta (denotes synapses with intact presynaptic and postsynaptic terminals) in extensions of WT neurons incubated with $\mathrm{A} \beta$ in the presence of $5 \mathrm{~nm}$ of uPA or its ATF (devoid of proteolytic activity). We found that $\mathrm{A} \beta$ decreases the number of bassoon/PSD-95-positive puncta, and that this effect is attenuated by uPA (Fig. $6 C, D$ ) via a mechanism that does not require plasmin generation (Fig. 6E,F). Importantly, A $\beta$ does not decrease the abundance of STX-I (Fig. $6 G$ ), indicating that, despite affecting the molecular composition of axonal boutons and dendritic spines, it does not alter the structural integrity of the presynaptic membrane. To further study the functional significance of these findings, we quantified the amplitude and frequency of sEPSCs in WT cerebral cortical neurons incubated during $24 \mathrm{~h}$ with vehicle (control) or $\mathrm{A} \beta$, alone or in the presence of uPA. Our data indicate that, compared with controls, $\mathrm{A} \beta$ causes a $35.4 \pm 3.8 \%$ and $32.78 \pm 6.8 \%$ decrease in the amplitude $(p=0.04)$ and frequency $(p=0.03)$ of EPSCs, respectively, and that this effect is abrogated by treatment with uPA $(p<0.05$, compared with cells treated with A $\beta$ alone; Fig. $6 E-J)$.
uPA regulates the synaptic expression and function of NCAD in cerebral cortical neurons

Our data indicate that $\mathrm{A} \beta$ decreases the synaptic abundance of bassoon and PSD-95, and that this harmful effect is attenuated by uPA. Because NCAD modulates the synaptic expression of bassoon and PSD-95 (Pielarski et al., 2013; Nikitczuk et al., 2014), we then investigated whether uPA has an effect on the synaptic expression and function of NCAD. Our studies with synaptoneurosomes and neuronal cultures prepared from WT and $\mathrm{uPAR}^{-1-}$ cerebral cortical neurons treated during $30 \mathrm{~min}$ with $5 \mathrm{nM}$ of uPA or a comparable volume of vehicle (control) indicate that $\mathrm{UPA}$ increases the abundance of NCAD in the synapse (Fig. $7 A, B$ ), and that, although this effect does not require plasmin generation (Fig. $7 C, D$ ), it is mediated by its binding to uPAR (Fig. 7E,F).

We then investigated whether uPA also induces the development of homophilic interactions between NCAD monomers, which is required for the formation of dendritic branches and synaptic contacts. Because the establishment of these interactions makes NCAD resistant to trypsin (Tanaka et al., 2000), we studied the expression of NCAD in WT cerebral cortical neurons incubated during $30 \mathrm{~min}$ with vehicle (control) or $5 \mathrm{~nm}$ of either uPA or its ATF, followed by treatment during $10 \mathrm{~min}$ with $0.006 \%$ trypsin. Our data indicate that uPA induces the formation of homophilic interactions between NCAD monomers, as denoted by attenuation of the proteolytic effect of trypsin in uPA-treated neurons (Fig. $7 G, H$ ), and that this effect does not require uPA's proteolytic activity (Fig. $7 I, J)$ ). To ensure that the 
A

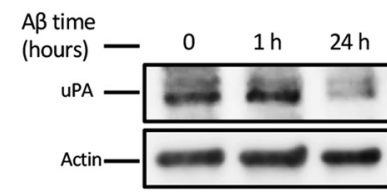

F

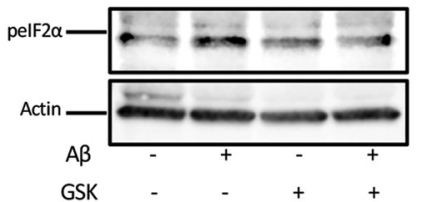

B

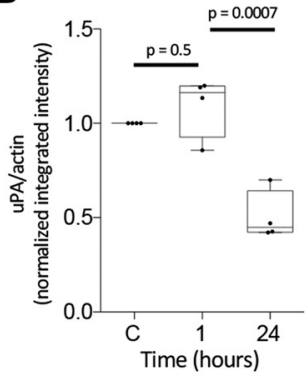

G

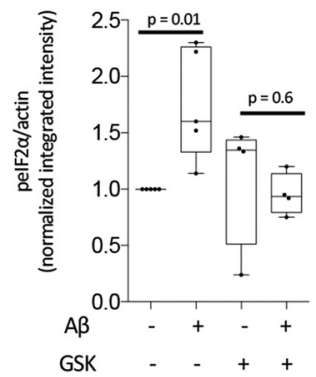

C

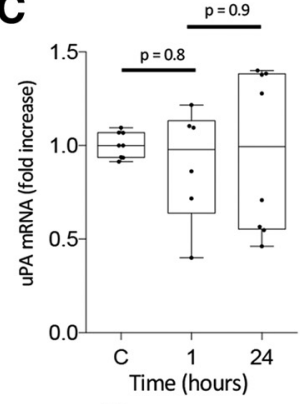

H
D
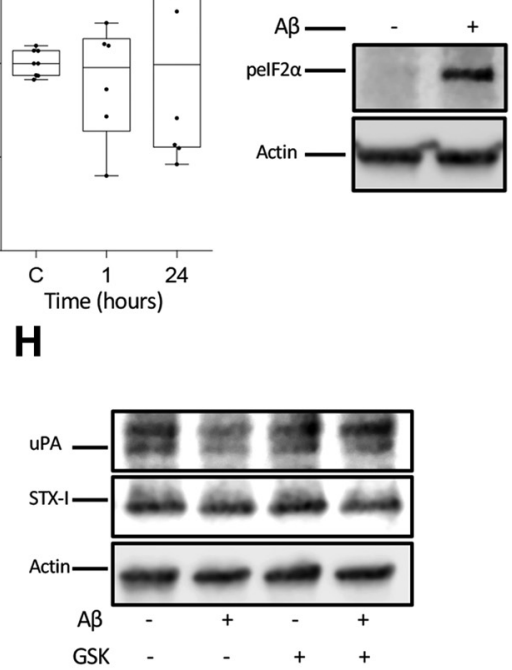

E

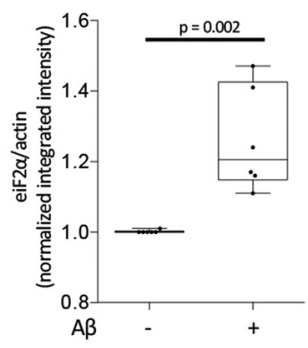

I

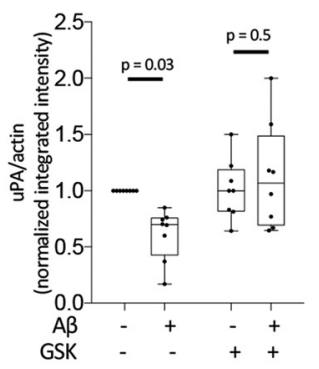

Figure 5. Effect of $A \beta$ on uPA mRNA translation. $\boldsymbol{A}, \boldsymbol{B}$, Representative Western blot analyses $(\boldsymbol{A})$ and quantification of the mean intensity of the band $(\boldsymbol{B})$ of uPA expression in WT cerebral cortical neurons incubated $0-24 \mathrm{~h}$ with $100 \mathrm{~nm}$ of $\mathrm{A} \beta$ 1-42 oligomers. $n=4$ per time point. Statistical analysis: one-way ANOVA with Tukey's multiple comparisons test. $C$, qRT-PCR analysis of uPA mRNA expression in WT cerebral cortical neurons exposed to the experimental conditions described in $\boldsymbol{A}$ and $\boldsymbol{D}$. $n=6-8$ per time point. Statistical analysis: one-way ANOVA with Tukey's multiple comparisons test. $\boldsymbol{D}, \boldsymbol{E}$, Representative Western blot analysis $(\boldsymbol{D})$ and quantification of the mean intensity of the band $(\boldsymbol{E})$ of pelf $2 \alpha$ in WT cerebral cortical neurons incubated 60 min with $100 \mathrm{~nm}$ of A $\beta$ 1-42 oligomers or vehicle (control). $n=6$ per experimental condition. Statistical analysis: two-tailed Student's $t$ test. $\boldsymbol{F}, \boldsymbol{G}$, Representative Western blot analysis $(\boldsymbol{F})$ and quantification of the mean intensity of the band (G) of pelF2 $\alpha$ in WT cerebral cortical neurons incubated 60 min with vehicle (control) or $100 \mathrm{~nm}$ of A $\beta 1-42$ oligomers, alone or in the presence of $1 \mu \mathrm{m}$ of the PERK inhibitor GSK 2606414 (GSK). $n=4$ per experimental condition. Statistical analysis: two-way ANOVA with Holm-Sidak's multiple comparisons test. $\boldsymbol{H}, \boldsymbol{I}$, Representative Western blot analysis $(\boldsymbol{H})$ and quantification of the mean intensity of the band $(\boldsymbol{I})$ of uPA expression in WT cerebral cortical neurons incubated $24 \mathrm{~h}$ with $100 \mathrm{~nm}$ of A $\beta 1-42$ oligomers, alone or in the presence of $1 \mu \mathrm{m}$ of the PERK inhibitor GSK 2606414 (GSK). $n=8$ per experimental condition. Statistical analysis: two-way ANOVA with Sidak's multiple comparisons test.

formation of these homophilic interaction leads to the development of NCAD dimers in the brain, the cerebral cortex of WT mice was treated during 30 min with $5 \mathrm{~nm}$ of uPA or a comparable volume of vehicle (control). Then synaptoneurosomes were prepared from both experimental groups, and Triton-insoluble and -soluble fractions were immunoblotted with anti-NCAD antibodies. We not only confirmed our original observation that uPA increases the abundance of NCAD monomers in the synapse (Fig. $7 K, L$ ) but also found that it induces the formation of NCAD dimers (apparent as a $230 \mathrm{kDa}$ band in the Triton-insoluble but not -soluble fraction; Fig. $7 K, M$ ). Because the generation of NCAD dimers triggers the formation of dendritic branches and modulates the expression of bassoon and PSD-95 in the synapse (Zhai et al., 2001; Togashi et al., 2002; Mendez et al., 2010), we quantified the number of dendritic branches and bassoon/ PSD-95-positive puncta in extensions from WT cerebral cortical neurons treated with uPA, alone or in the presence of $175 \mu \mathrm{M}$ of the NCAD inhibitor ADH1 (prevents the formation of NCAD dimers). We found that uPA induces the formation of dendritic branches (Fig. $7 \mathrm{~N}, \mathrm{O}$ ) and bassoon/PSD-95-expressing synaptic contacts (Fig. $7 P, Q$ ), and that both effects are mediated by the generation of NCAD dimers, as they are abrogated by ADH1.

\section{UPA-induced formation of NCAD dimers protects the} synapse and dendritic branches from the harmful effects of $A \beta$

Our confocal microscopy studies show that the expression of NCAD is decreased in the II/III layers of the frontal cortex of $\mathrm{AD}$ patients (Fig. $8 A, B$ ) and 6 -month-old $5 \mathrm{xFAD}$ mice (Fig. $8 C$,
$D)$. We then decided to study the expression of NCAD in WT cerebral cortical neurons after $24 \mathrm{~h}$ of incubation with $100 \mathrm{~nm}$ of A $\beta$ 1-42 oligomers, in the presence of $5 \mathrm{~nm}$ of uPA or its ATF, or a comparable volume of vehicle (control). A subset of neurons was treated with a combination of uPA and $4 \mu \mathrm{g} / \mathrm{ml}$ of antiUPAR blocking antibodies. These experiments revealed that $\mathrm{A} \beta$ decreases the expression of NCAD, and that this effect is abrogated by uPA (Fig. $8 E, F$ ) via a uPAR-mediated mechanism (Fig. $8 G, H$ ) that does not require plasmin generation (Fig. $8 I, J$ ). More importantly, we found that the harmful effect of $\mathrm{A} \beta$ on the number of dendritic branches (Fig. $8 K, L$ ) and intact synaptic contacts (Fig. $8 M, N$ ) is attenuated by uPA, and that this protective effect is mediated by the formation of NCAD dimers as it was abrogated by cotreatment with ADH1.

\section{Discussion}

The cerebral cortex has six layers with more or less well-differentiated populations of cells (DeFelipe et al., 2006). Hence, while layers I and IV contain mostly neuropil (layer I) and stellate neurons (layer IV) with locally ramifying axons, layers II/III and V harbor pyramidal neurons that establish excitatory connections with other areas of the brain (DeFelipe et al., 2006). Our confocal microscopy studies show that uPA is abundantly found in the II/ III and V cortical layers of the frontal cortex, and that this expression pattern is similar in the murine and human brain. Furthermore, we show that glutamate, at concentrations that increase synaptic activity and induce neuronal plasticity, promotes its release via a calcium-dependent mechanism. Importantly, although astrocytes (Diaz et al., 2019) and endothelial cells (Prager 
A
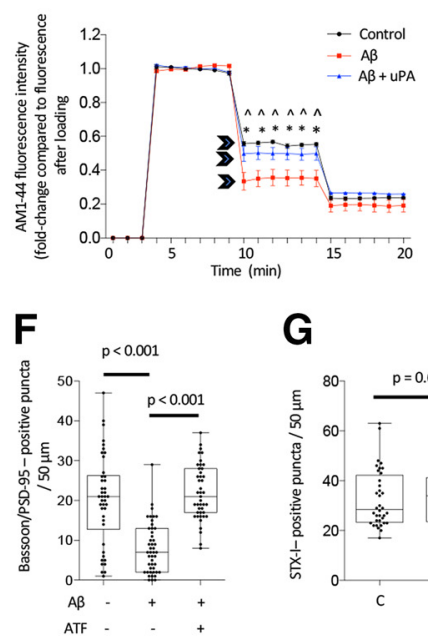

G

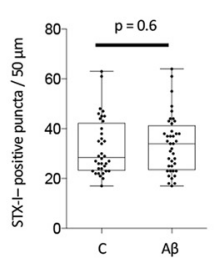

B

C

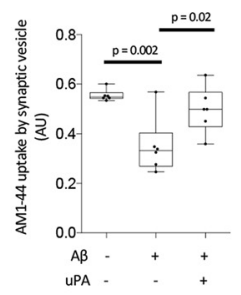

H

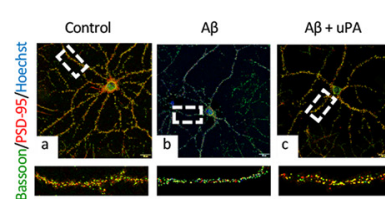

E

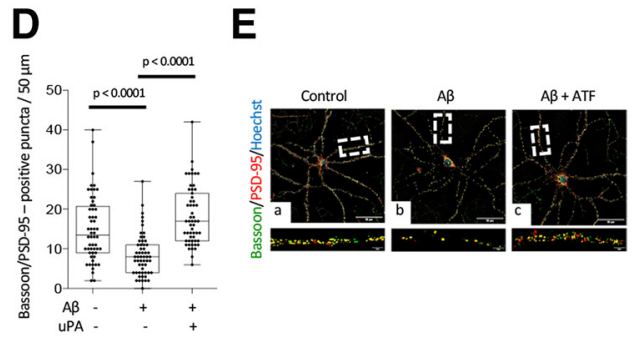

Figure 6. UPA protects the synapse from the harmful effects of $A \beta . A, B$, WT cerebral cortical neurons incubated during $24 \mathrm{~h}$ with $100 \mathrm{~nm}$ of $\mathrm{A} \beta \quad 1-42$ oligomers, alone or in combination with $5 \mathrm{nM}$ of $\mathrm{UPA}$, or with vehicle (control), were treated with a combination of $5 \mu \mathrm{m}$ of AM1-44 and $45 \mathrm{~mm}$ of KCl. Cells were then washed and treated 5 min later with $5 \mu \mathrm{m}$ of ADVASEP-7 to reduce background and induce the release of membrane-bound AM1-44. Fluorescence intensity at this point corresponds to AM1-44 loaded into presynaptic vesicles (depicted with an arrow). Five minutes later, cells were treated with $45 \mathrm{~nm}$ of $\mathrm{KCl}$ to induce the release of AM1-44 incorporated into synaptic vesicles. $\boldsymbol{B}$, Values indicate fluorescence intensity before second dose of KCl (AM1-44 loaded into synaptic vesicles). Each experiment was repeated six times for a total of 30 observations per experimental condition. $\boldsymbol{A}, p<0.05$ when $\mathrm{A} \beta$-treated cells are compared with $\mathrm{A} \beta / \mathrm{uPA}^{(*)}$ and vehicle (control)-treated (a) neurons. $\boldsymbol{A}, \boldsymbol{B}$, Statistical analysis: two-way $(\boldsymbol{A})$ and one-way $(\boldsymbol{B})$ ANOVA with Tukey's multiple comparisons test. $\boldsymbol{C}-\boldsymbol{F}$, Representative confocal micrographs of WT cerebral cortical neurons incubated during $24 \mathrm{~h}$ with $\mathrm{A} \beta$, alone or in the presence of either UPA $(\boldsymbol{C})$ or its ATF $(\boldsymbol{E})$ an immunostained with Hoechst and antibodies against bassoon (green) and PSD-95 (red). Bottom panels, The $4 \times$ magnification of the area depicted by the dashed squares. $\boldsymbol{D}, \boldsymbol{F}$, The mean number of bassoon/PSD-95-p0sitive puncta in neuronal extension of WT neurons exposed to the experimental conditions described in $\boldsymbol{C}$ and $\boldsymbol{E}$, respectively. $\boldsymbol{D}, n=56 . \boldsymbol{F}, n=40$. Statistical analysis: one-way ANovA with Tukey's multiple comparisons test. G, Mean number of STX-I-positive puncta in extensions of WT neurons incubated $24 \mathrm{~h}$ with $100 \mathrm{~nm}$ of A $\beta$ 1-42 oligomers or a comparable volume of vehicle (control). $n=40$. Statistical analysis: two-tailed Student's $t$ test. $\boldsymbol{H}$, Representative recordings of sEPSCs in WT cerebral cortical incubated during $24 \mathrm{~h}$ with vehicle (control) or A $\beta$, alone or in combination with uPA. I, J, Mean amplitude ( () and frequency (J) of sEPSCs in WT cerebral cortical neurons exposed to the experimental conditions described in $\boldsymbol{H}$. $n=23$ (control cells), 24 (cells treated with $A \beta$ alone), and 18 (cells treated with $A \beta$ in the presence of uPA). Results are presented as percentage of amplitude and frequency in relation to control cells. Each observation was repeated with cells from 5 different cultures. Statistical analysis: one-way ANOVA with Holm-Sidak's multiple comparisons test.

et al., 2004) also express uPA, our studies with synaptoneurosomes indicate that, in the cerebral cortex and cultured cerebral cortical neurons, most of uPA is found in the synapse. However, it is important to note that we also detected a less intense band of immunoreactivity to anti-uPA antibodies in whole-brain extracts that may correspond to uPA in glia, endothelial cells, and the shaft of neuronal extensions.

The PA system plays a role in the pathogenesis of $\mathrm{AD}$ (Barker et al., 2010). However, most of the studies published to this date have focused on the effect of a dysfunctional tPA-plasminogenplasmin cascade on plasmin-mediated cleavage of $A \beta$ plaques in advanced stages of the disease (Tucker et al., 2000; Melchor et al., 2003). In contrast, the role of uPA in the pathophysiology of AD remains unknown. Our work indicates that the abundance of $\mathrm{uPA}$, but not uPAR, is decreased in the synapse of neurons located in the II/III and V layers of the frontal cortex of patients with $\mathrm{AD}$ and $5 \mathrm{xFAD}$ mice. Furthermore, we show that this effect is specific to neurons as it is not observed in astrocytes, or in other organs, such as aorta and kidneys. Noticeably, we detected increased GFAP immunoreactivity in some extracts from 5xFAD astrocytes, which agrees with the reported increase in astrocytic activation in 5xFAD mice (Sompol et al., 2017). Independently of these considerations, our observations agree with a reported decrease in the abundance of uPA in the plasma of patients with early stages of AD (Whelan et al., 2019). We found that the synaptic expression of uPA is already decreased in the early stages of the disease, when $\mathrm{A} \beta$ levels in the cerebral cortex are increased but $\mathrm{A} \beta$ deposits are absent. These results are in line with our observations that soluble $\mathrm{A} \beta$ oligomers decrease the synaptic abundance of UPA, but not UPAR, and that this effect is unique to neurons, as in our experimental paradigm $\mathrm{A} \beta$ failed to decrease the expression of uPA in astrocytes.

The unfolded protein response is crucial for cellular homeostasis through transcriptional regulation of proteostasis pathways in the endoplasmic reticulum via three stress-responsive transmembrane proteins: PERK, inositol requiring element 1 , and activating transcription factor 6 (Genereux et al., 2015). PERK induces the phosphorylation of eIF2 $\alpha$ (Marciniak et al., 2006), which in turn produces a general translational halt. The unfolded protein response is upregulated in the brain of $\mathrm{AD}$ patients before the formation of plaques and tangles (Hoozemans et al., 2009), and several lines of evidence indicate that peIF $2 \alpha$ shuts down mRNA translation in $\mathrm{AD}$ and other neurodegenerative diseases (Chang et al., 2002), and that this effect is associated with synaptic dysfunction and memory deficits (Ma et al., 2013). Our data show that $\mathrm{A} \beta$ increases the abundance of peIF $2 \alpha$, and that inhibition of PERK abrogates the harmful effect of $\mathrm{A} \beta$ on the expression of uPA protein. Significantly, PERK and eIF2 $\alpha$ are also found in astrocytes (Guthrie et al., 2016), so A $\beta$ should interact with an as yet unknown synaptic site or protein unique to neurons to inhibit the translation of uPA mRNA in these cells but not in astrocytes. More importantly, our results unveil a new modulatory role of uPA on the unfolded protein response in neurons, with translational implications for the treatment of patients with $\mathrm{AD}$ and other neurodegenerative diseases.

Synaptic dysfunction is an early event in AD (Selkoe, 2002) that precedes the deposition of $\mathrm{A} \beta$ (Hsia et al., 1999) and correlates with the development of cognitive symptoms better than the number of plaques and tangles (Terry et al., 1991). Indeed, the accumulation and deposition of $\mathrm{A} \beta$ in the brain are not 
A

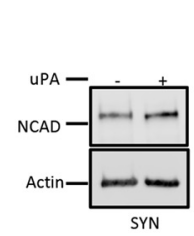

B
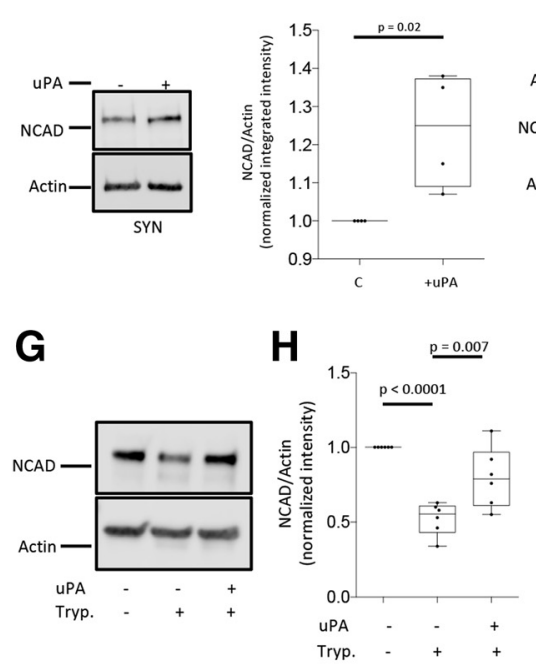

I

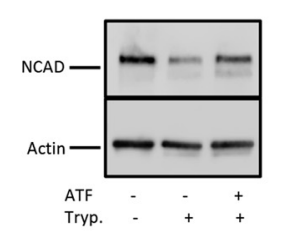

J

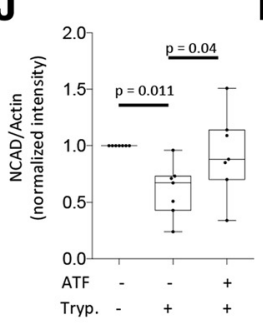

E

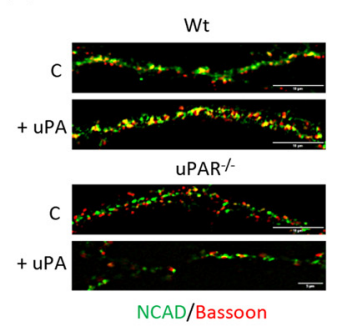

K

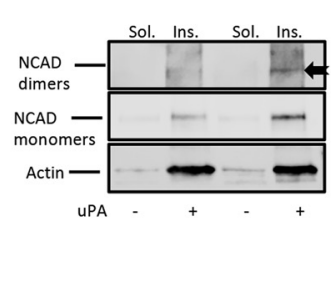

P

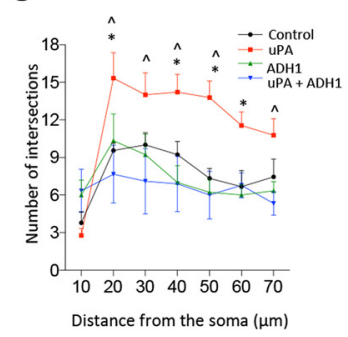

0

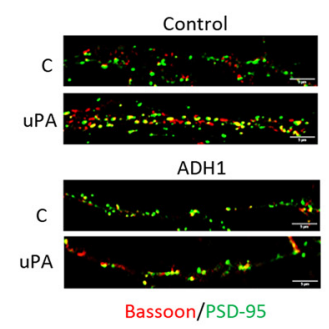

N

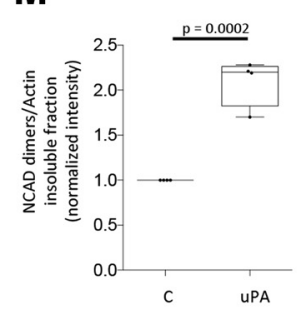

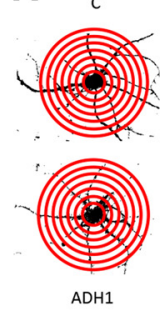

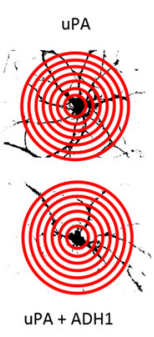

F

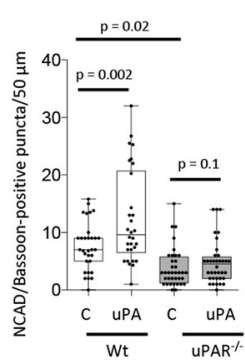

L

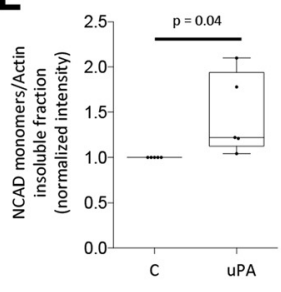

Q

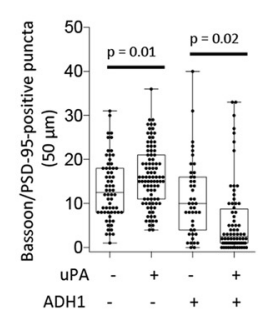

Figure 7. uPA regulates the expression and function of NCAD in the synapse. $A-D$, Representative Western blot analyses $(A, C)$ and quantification of the mean intensity of the band (B, $D)$ of NCAD expression in synaptoneurosomes (SYN) prepared from WT cerebral cortical neurons incubated 30 min with vehicle (control) or $5 \mathrm{nM}$ of either uPA $(\boldsymbol{A}, \boldsymbol{B})$ or its ATF $(\boldsymbol{C}, \boldsymbol{D})$. $n=4$. Statistical analysis: two-tailed Student's $t$ test. $E$, Representative confocal micrographs at $240 \times$ magnification of WT and uPAR ${ }^{-1-}$ neurons immunostained with anti-NCAD (green) and -bassoon (red) antibodies after 30 min of uPA treatment. $\boldsymbol{F}$, Mean number of NCAD/bassoon-positive puncta in extensions from WT $(n=31)$ and uPAR ${ }^{-1-}(n=36)$ neurons treated as described in C. Statistical analysis: two-tailed Student's $t$ test. $\mathbf{G}-\boldsymbol{J}$, Representative Western blot analyses $(\boldsymbol{G}, \boldsymbol{I})$ and quantification of the mean intensity of the band $(\boldsymbol{H}, \boldsymbol{J})$ of NCAD expression in WT neurons incubated during $30 \mathrm{~min}$ with $5 \mathrm{~nm}$ of either uPA $(\boldsymbol{G}, \boldsymbol{H})$ or its ATF $(\boldsymbol{I}, \boldsymbol{J})$ followed by $10 \mathrm{~min}$ of treatment with $0.006 \%$ trypsin. $n=6$ per condition. Statistical analysis: one-way ANOVA with Tukey's multiple comparisons test. $\boldsymbol{K}-\boldsymbol{M}$, Representative Western blot analysis $(\boldsymbol{K})$ and normalized intensity of the band $(\boldsymbol{L}, \boldsymbol{M})$ of NCAD monomers $(\boldsymbol{K}, \boldsymbol{L})$ and dimer expression (black arrow in $\boldsymbol{K}$; quantification in $\boldsymbol{M}$ ) in the soluble (Sol.) and insoluble (Ins.) fractions of extracts prepared from the cerebral cortex of WT mice following treatment with uPA. $n=4$ per condition. Statistical analysis: two-tailed Student's $t$ test. $\boldsymbol{N}, \mathbf{0}$, Representative Sholl analyses $(\boldsymbol{N})$ and mean number of dendritic intersections $0-70 \mu \mathrm{m}$ from the neuronal soma $(\mathbf{0})$ in WT cerebral cortical neurons treated with either vehicle (control), or $5 \mathrm{~nm}$ of uPA, or $175 \mu \mathrm{m}$ of the NCAD inhibitor ADH1, or a combination of UPA and ADH1. * $p<0.05$ compared with neurons treated with vehicle (control). a $p<0.05$ compared with neurons treated with uPA and ADH1. $n=90$ cells/per condition. Lines indicate SEM. Statistical analysis: two-way ANOVA with Dunnett's multiple comparison test. $\boldsymbol{P}, \mathbf{Q}$, Representative confocal micrographs $(240 \times)$ of extensions of WT neurons immunostained with antibodies against bassoon (red) and-PSD-95 (green) after 30 min of treatment with UPA or vehicle (control), alone or in the presence of the NCAD inhibitor ADH1. Q, The mean number of bassoon/PSD-95-positive puncta in 64-93 extensions from neurons exposed to the experimental conditions described in $\boldsymbol{P}$. Statistical analysis: one-way ANOVA with Holm-Sidak's comparisons test.

sufficient to cause cognitive symptoms (Price and Morris, 1999; Aizenstein et al., 2008), and multiple studies have shown that soluble $\mathrm{A} \beta$ is more toxic than the aggregate forms (Jin et al., 2011). Accordingly, several lines of experimental work have shown that soluble A $\beta$ oligomers have a harmful effect on the synapse (Fitzjohn et al., 2001; Selkoe, 2002; Lacor et al., 2007), and that cortical levels of soluble $\mathrm{A} \beta$ correlate with synaptic dysfunction (Lue et al., 1999) and loss of synaptic proteins, such as bassoon and PSD-95 (Almeida et al., 2005). Our data indicate that $\mathrm{A} \beta$ impairs synaptic function and that this effect is abrogated by treatment with uPA. In contrast, in our experimental paradigm, $\mathrm{A} \beta$ did not alter the structural integrity of the presynaptic membrane, as denoted by unchanged levels of STX-I in $\mathrm{A} \beta$-treated neurons. These observations are in line with reports indicating that $\mathrm{A} \beta$ has a negative effect on the molecular composition of the synapse without causing structural damage to the axonal bouton and postsynaptic terminal (Chapman et al., 1999). Our observations are novel for four reasons: (1) this is the first report that neuronal uPA protects the synapse from the harmful effect of $\mathrm{A} \beta$; (2) it indicates that this protective role is mediated by UPAR and independent of uPA's ability to cleave plasminogen into plasmin; (3) it shows that $\mathrm{A} \beta$ does not have an effect on the abundance of UPAR, thus opening the possibility of using recombinant uPA to reverse the harmful effects of $\mathrm{A} \beta$ on the synapse; and (4) it indicates that uPA plays a crucial role in the early stages of the disease.

Cadherins are a family of proteins that mediate the formation of adherent contacts between apposing membranes (Geiger and Ayalon, 1992). A link between cadherins and uPA has been proposed in various experimental systems. Accordingly, some studies have shown that E-cadherin increases the expression of uPA in different cell lines and tumors (Frixen and Nagamine, 1993; Sasaki et al., 1999; Hiendlmeyer et al., 2004; Kleiner et al., 2007), and others have reported that E-cadherin mediates the ability of uPA to promote the dissemination of malignant cells (Munshi et al., 2002). We found that uPA increases the abundance of NCAD 


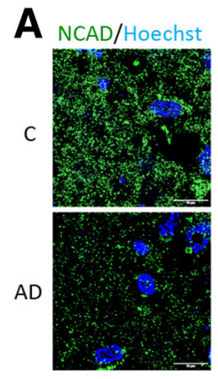

B

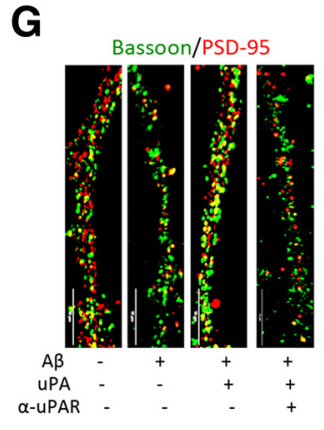

L

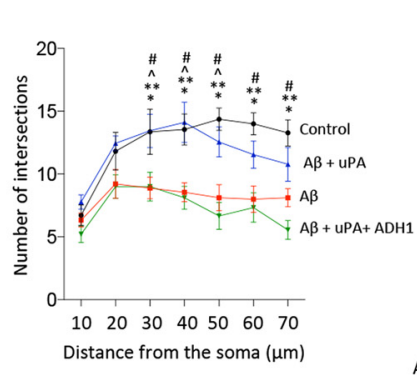

H

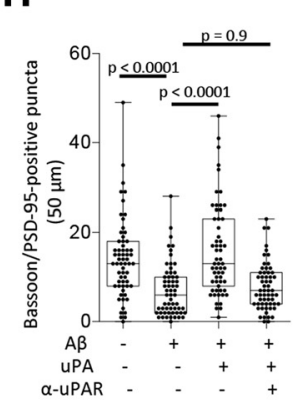

I

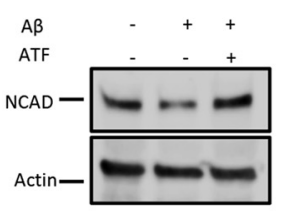

M

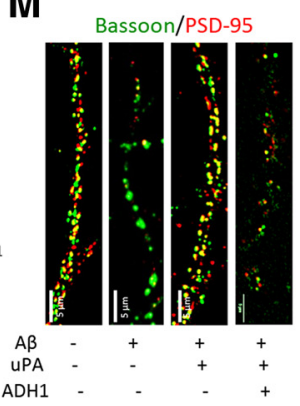

N

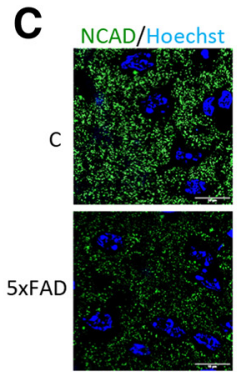

D

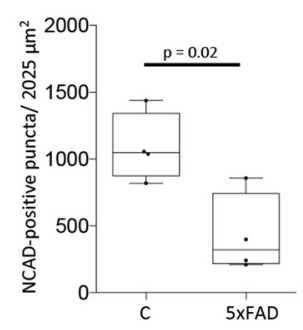

E

F
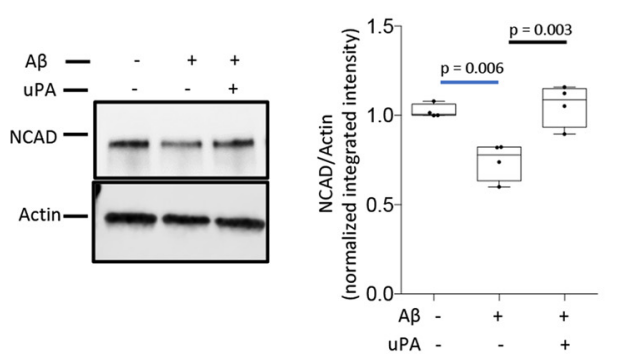

J

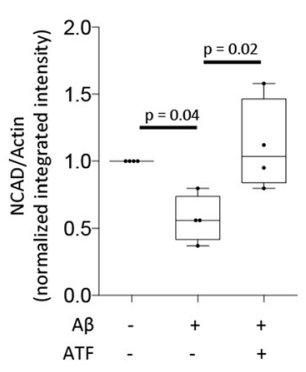

K

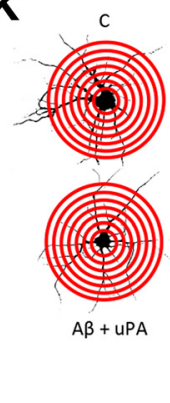

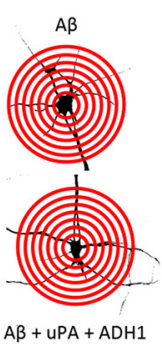

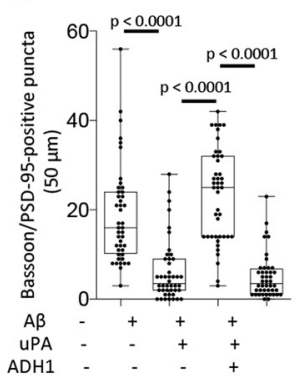

Figure 8. uPA-induced formation of NCAD dimers protects against A $\beta$-induced damage of dendritic branches and synapses. A-D, Representative confocal micrographs at $282 \times$ magnification of the II/III cortical layers of the frontal cortex of the brain of AD patients or healthy controls $(\boldsymbol{A})$, or $5 x \mathrm{xFD}$ mice and their WT littermate controls $(\boldsymbol{C})$, immunostained with Hoechst (blue) and antibodies against NCAD (green). $\boldsymbol{B}, \boldsymbol{D}$, The mean number of NCAD-positive puncta/2025 $\mu \mathrm{m}^{2}$ in each experimental group. $n=5$ brains and 5 micrographs per brain in $\boldsymbol{B}$, and 4 brains and 5 micrographs per brain in $\boldsymbol{D}$. $\boldsymbol{B}, \boldsymbol{D}$, Statistical analysis: two-tailed Student's $t$ test. $\boldsymbol{E}, \boldsymbol{F}$, Representative Western blot analysis $(\boldsymbol{E})$ and quantification of the mean intensity of the band $(\boldsymbol{F})$ of NCAD expression in extracts from WT cerebral cortical neurons incubated during $24 \mathrm{~h}$ with vehicle (control) or A $\beta$ 1-42 oligomers, alone or in the presence of $5 \mathrm{~nm}$ of uPA or vehicle (control). $n=4$ per experimental condition. Statistical analysis: one-way ANOVA with Tukey's multiple comparisons test. $\boldsymbol{G}, \boldsymbol{H}$, Representative confocal micrographs $(240 \times)$ of extensions of WT neurons immunostained with antibodies against bassoon (green) and-PSD-95 (red) after $24 \mathrm{~h}$ of incubation with A $\beta$, alone or in the presence of $5 \mathrm{~nm}$ of uPA, alone or in combination with $4 \mu \mathrm{g} / \mathrm{ml}$ of anti-uPAR antibodies or an lgG isotype (control). $\boldsymbol{H}$, The mean number of bassoon/PSD-95-positive puncta in 60 extensions from neurons exposed to the experimental conditions described in G. Statistical analysis: one-way ANOVA with Tukey's multiple comparisons test. $I, J$, Representative Western blot analysis $(\boldsymbol{I})$ and quantification of the mean intensity of the band $(\boldsymbol{I})$ of NCAD expression in extracts from WT cerebral cortical neurons incubated during $24 \mathrm{~h}$ with vehicle (control) or A $\beta$ 1-42 oligomers, alone or in the presence of $5 \mathrm{~nm}$ of uPA's AFT. $n=4$ per experimental condition. Statistical analysis: one-way ANOVA with Tukey's multiple comparisons test. $\boldsymbol{K}, \boldsymbol{L}$, Representative Sholl analyses $(\boldsymbol{K})$ and mean number of dendritic intersections $0-70 \mu \mathrm{m}$ from the neuronal soma $(\boldsymbol{L})$ in WT cerebral cortical neurons incubated $24 \mathrm{~h}$ with $100 \mathrm{~nm}$ of soluble $A \beta \quad 1-42$ oligomers, alone or in the presence of $5 \mathrm{~nm}$ of uPA, alone or in combination with $175 \mu \mathrm{m}$ of the NCAD inhibitor ADH1. $n=45$ cells examined per experimental group. $p<0.05$ when controls are compared with neurons treated with $A \beta\left(^{*}\right)$ or $A \beta+$ uPA $(* *)$; or when cells treated with $A \beta$ are compared with cells treated with $A \beta+$ uPA $(\wedge)$; or when cells treated with $A \beta+$ uPA are compared with cells treated with $A \beta+$ uPA + ADH1 (\#). Lines indicate SEM. Statistical analysis: two-way ANOVA with Tukey's multiple comparison test. $\boldsymbol{M}, \boldsymbol{N}$, Representative confocal micrographs $(240 \times)$ of extensions of WT neurons immunostained with antibodies against bassoon (green) and-PSD-95 (red) after $24 \mathrm{~h}$ of incubation with $\mathrm{A} \beta$, alone or in the presence of $5 \mathrm{~nm}$ of $\mathrm{UPA}$, or with a combination of A $\beta$, uPA, and ADH1. $\boldsymbol{N}$, The mean number of bassoon/PSD-95-positive puncta in 44 extensions from neurons exposed to the experimental conditions described in $\boldsymbol{M}$. Statistical analysis: one-way ANOVA with Tukey's multiple comparisons test.

in the synapse and induces the development of NCAD dimers in the cerebral cortex, and that this leads to the formation of dendritic branches and bassoon/PSD-95-containing synaptic contacts. Furthermore, we found that the expression of NCAD is decreased in the cerebral cortex of $\mathrm{AD}$ patients and $5 \mathrm{xFAD}$ mice, and in WT cerebral cortical neurons incubated with $\mathrm{A} \beta$. These observations agree with reports indicating that $\mathrm{A} \beta$ decreases the expression of NCAD in the synapse of the frontal cortex of AD patients (Ando et al., 2011). More importantly, our results indicate that uPA treatment abrogates the harmful effect of $\mathrm{A} \beta$ on
NCAD expression, and that uPA-induced formation of NCAD dimers protects the synapse and dendritic branches from the deleterious effect of soluble $\mathrm{A} \beta$.

Synaptic activity (Kamenetz et al., 2003) and sublethal NMDAR activation (Lesne et al., 2005) induce the release of A $\beta$ and increase its levels in the interstitial space (Cirrito et al., 2005). Because our data show that glutamate, at doses that increase synaptic activity without inducing cell death, also induces the release of neuronal uPA, then we propose a model in which synaptic activity induces the release of both $\mathrm{A} \beta$ and uPA. 
In the early stages of this process, uPA counteracts the toxic effect of $\mathrm{A} \beta$ by increasing the abundance of NCAD in the synapse. However, this homeostatic effect is lost when high concentrations of $\mathrm{A} \beta$ halt the translation of uPA mRNA by inducing PERK-mediated phosphorylation of eIF $2 \alpha$. We acknowledge that the PERK inhibitor used in our studies may have unknown unintended off site effects. However, our demonstration that it effectively inhibits $\mathrm{A} \beta$-induced eIF $2 \alpha$ phosphorylation supports our hypothesis that $\mathrm{A} \beta$ has a negative effect on uPA expression via PERK-mediated eIF2 $\alpha$ phosphorylation. Significantly, A $\beta$ decreases NCAD, but not uPAR expression in the synapse. Thus, by triggering the formation of NCAD dimers, binding of recombinant uPA to endogenous uPAR is capable to rescue synapses and dendritic branches from the harmful effects of $\mathrm{A} \beta$. This is a novel role for uPA with important implications for the understanding of the pathophysiological events that cause early synaptic dysfunction in $\mathrm{AD}$, and for the development of potential therapeutic strategies to protect the synapse before the progression to irreversible brain damage.

\section{References}

Aizenstein HJ, Nebes RD, Saxton JA, Price JC, Mathis CA, Tsopelas ND, Ziolko SK, James JA, Snitz BE, Houck PR, Bi W, Cohen AD, Lopresti BJ, DeKosky ST, Halligan EM, Klunk WE (2008) Frequent amyloid deposition without significant cognitive impairment among the elderly. Arch Neurol 65:1509-1517.

Almeida CG, Tampellini D, Takahashi RH, Greengard P, Lin MT, Snyder EM, Gouras GK (2005) Beta-amyloid accumulation in APP mutant neurons reduces PSD-95 and GluR1 in synapses. Neurobiol Dis 20:187-198.

Ando K, Uemura K, Kuzuya A, Maesako M, Asada-Utsugi M, Kubota M, Aoyagi N, Yoshioka K, Okawa K, Inoue H, Kawamata J, Shimohama S, Arai T, Takahashi R, Kinoshita A (2011) N-cadherin regulates p38 MAPK signaling via association with JNK-associated leucine zipper protein: implications for neurodegeneration in Alzheimer disease. J Biol Chem 286:7619-7628.

Asada-Utsugi M, Uemura K, Noda Y, Kuzuya A, Maesako M, Ando K, Kubota M, Watanabe K, Takahashi M, Kihara T, Shimohama S, Takahashi R, Berezovska O, Kinoshita A (2011) N-cadherin enhances APP dimerization at the extracellular domain and modulates Abeta production. J Neurochem 119:354-363.

Barker R, Love S, Kehoe PG (2010) Plasminogen and plasmin in Alzheimer's disease. Brain Res 1355:7-15.

Benson DL, Tanaka H (1998) N-cadherin redistribution during synaptogenesis in hippocampal neurons. J Neurosci 18:6892-6904.

Buskila Y, Crowe SE, Ellis-Davies GC (2013) Synaptic deficits in layer 5 neurons precede overt structural decay in $5 \mathrm{xFAD}$ mice. Neuroscience 254:152-159.

Chang RC, Wong AK, Ng HK, Hugon J (2002) Phosphorylation of eukaryotic initiation factor-2alpha (eIF2alpha) is associated with neuronal degeneration in Alzheimer's disease. Neuroreport 13:2429-2432.

Chapman PF, White GL, Jones MW, Cooper-Blacketer D, Marshall VJ, Irizarry M, Younkin L, Good MA, Bliss TV, Hyman BT, Younkin SG, Hsiao KK (1999) Impaired synaptic plasticity and learning in aged amyloid precursor protein transgenic mice. Nat Neurosci 2:271-276.

Cirrito JR, Yamada KA, Finn MB, Sloviter RS, Bales KR, May PC, Schoepp DD, Paul SM, Mennerick S, Holtzman DM (2005) Synaptic activity regulates interstitial fluid amyloid-beta levels in vivo. Neuron 48:913-922.

Collen D (1999) The plasminogen (fibrinolytic) system. Thromb Haemost $82: 259-270$

Davies CA, Mann DM, Sumpter PQ, Yates PO (1987) A quantitative morphometric analysis of the neuronal and synaptic content of the frontal and temporal cortex in patients with Alzheimer's disease. J Neurol Sci 78:151-164.

Davis J, Wagner MR, Zhang W, Xu F, Van Nostrand WE (2003) Amyloid beta-protein stimulates the expression of urokinase-type plasminogen activator ( $\mathrm{uPA}$ ) and its receptor ( $\mathrm{UPAR}$ ) in human cerebrovascular smooth muscle cells. J Biol Chem 278:19054-19061.
DeFelipe J, Ballesteros-Yáñez I, Inda MC, Muñoz A (2006) Double-bouquet cells in the monkey and human cerebral cortex with special reference to areas 17 and 18. Prog Brain Res 154:15-32.

DeKosky ST, Scheff SW (1990) Synapse loss in frontal cortex biopsies in Alzheimer's disease: correlation with cognitive severity. Ann Neurol 27:457-464.

Diaz A, Merino P, Manrique LG, Ospina JP, Cheng L, Wu F, Jeanneret V, Yepes M (2017) A cross-talk between neuronal urokinase-type plasminogen activator ( $\mathrm{uPA})$ and astrocytic $\mathrm{uPA}$ receptor (uPAR) promotes astrocytic activation and synaptic recovery in the ischemic brain. J Neurosci 37:10310-10322.

Diaz A, Merino P, Manrique LG, Cheng L, Yepes M (2019) Urokinase-type plasminogen activator ( $\mathrm{uPA}$ ) protects the tripartite synapse in the ischemic brain via ezrin-mediated formation of peripheral astrocytic processes. J Cereb Blood Flow Metab 39:2157-2171.

Echeverry R, Wu J, Haile WB, Guzman J, Yepes M (2010) Tissue-type plasminogen activator is a neuroprotectant in the mouse hippocampus. J Clin Invest 120:2194-2205.

Fa M, Orozco IJ, Francis YI, Saeed F, Gong Y, Arancio O (2010) Preparation of oligomeric beta-amyloid 1-42 and induction of synaptic plasticity impairment on hippocampal slices. J Vis Exp 41:1884.

Fitzjohn SM, Morton RA, Kuenzi F, Rosahl TW, Shearman M, Lewis H, Smith D, Reynolds DS, Davies CH, Collingridge GL, Seabrook GR (2001) Age-related impairment of synaptic transmission but normal long-term potentiation in transgenic mice that overexpress the human APP695SWE mutant form of amyloid precursor protein. J Neurosci 21:4691-4698.

Frixen UH, Nagamine Y (1993) Stimulation of urokinase-type plasminogen activator expression by blockage of E-cadherin-dependent cell-cell adhesion. Cancer Res 53:3618-3623.

Geiger B, Ayalon O (1992) Cadherins. Annu Rev Cell Biol 8:307-332.

Genereux JC, Qu S, Zhou M, Ryno LM, Wang S, Shoulders MD, Kaufman RJ, Lasmezas CI, Kelly JW, Wiseman RL (2015) Unfolded protein response-induced ERdj3 secretion links ER stress to extracellular proteostasis. EMBO J 34:4-19.

Guthrie LN, Abiraman K, Plyler ES, Sprenkle NT, Gibson SA, McFarland BC, Rajbhandari R, Rowse AL, Benveniste EN, Meares GP (2016) Attenuation of PKR-like ER kinase (PERK) signaling selectively controls endoplasmic reticulum stress-induced inflammation without compromising immunological responses. J Biol Chem 291:15830-15840.

He Y, Wei M, Wu Y, Qin H, Li W, Ma X, Cheng J, Ren J, Shen Y, Chen Z, Sun B, Huang FD, Shen Y, Zhou YD (2019) Amyloid beta oligomers suppress excitatory transmitter release via presynaptic depletion of phosphatidylinositol-4,5-bisphosphate. Nat Commun 10:1193.

Hiendlmeyer E, Regus S, Wassermann S, Hlubek F, Haynl A, Dimmler A, Koch C, Knoll C, van Beest M, Reuning U, Brabletz T, Kirchner T, Jung A (2004) Beta-catenin up-regulates the expression of the urokinase plasminogen activator in human colorectal tumors. Cancer Res 64:12091214.

Honjo Y, Nakagawa S, Takeichi M (2000) Blockade of cadherin-6B activity perturbs the distribution of PSD-95 family proteins in retinal neurones. Genes Cells 5:309-318.

Hoozemans JJ, van Haastert ES, Nijholt DA, Rozemuller AJ, Eikelenboom P, Scheper W (2009) The unfolded protein response is activated in pretangle neurons in Alzheimer's disease hippocampus. Am J Pathol 174:12411251.

Hsia AY, Masliah E, McConlogue L, Yu GQ, Tatsuno G, Hu K, Kholodenko D, Malenka RC, Nicoll RA, Mucke L (1999) Plaque-independent disruption of neural circuits in Alzheimer's disease mouse models. Proc Natl Acad Sci USA 96:3228-3233.

Jacobsen JS, Wu CC, Redwine JM, Comery TA, Arias R, Bowlby M, Martone R, Morrison JH, Pangalos MN, Reinhart PH, Bloom FE (2006) Earlyonset behavioral and synaptic deficits in a mouse model of Alzheimer's disease. Proc Natl Acad Sci USA 103:5161-5166.

Jeanneret V, Ospina JP, Diaz A, Manrique LG, Merino P, Gutierrez L, Torre E, Wu F, Cheng L, Yepes M (2018) Tissue-type plasminogen activator protects the postsynaptic density in the ischemic brain. J Cereb Blood Flow Metab 38:1896-1910.

Jin M, Shepardson N, Yang T, Chen G, Walsh D, Selkoe DJ (2011) Soluble amyloid beta-protein dimers isolated from Alzheimer cortex directly induce Tau hyperphosphorylation and neuritic degeneration. Proc Natl Acad Sci USA 108:5819-5824. 
Kamenetz F, Tomita T, Hsieh H, Seabrook G, Borchelt D, Iwatsubo T, Sisodia S, Malinow R (2003) APP processing and synaptic function. Neuron 37:925-937.

Kawarabayashi T, Younkin LH, Saido TC, Shoji M, Ashe KH, Younkin SG (2001) Age-dependent changes in brain, CSF, and plasma amyloid (beta) protein in the $\operatorname{Tg} 2576$ transgenic mouse model of Alzheimer's disease. J Neurosci 21:372-381.

Kleiner S, Faisal A, Nagamine Y (2007) Induction of uPA gene expression by the blockage of E-cadherin via Src- and Shc-dependent Erk signaling. FEBS J 274:227-240.

Lacor PN, Buniel MC, Furlow PW, Clemente AS, Velasco PT, Wood M, Viola KL, Klein WL (2007) Abeta oligomer-induced aberrations in synapse composition, shape, and density provide a molecular basis for loss of connectivity in Alzheimer's disease. J Neurosci 27:796-807.

Lambert MP, Barlow AK, Chromy BA, Edwards C, Freed R, Liosatos M, Morgan TE, Rozovsky I, Trommer B, Viola KL, Wals P, Zhang C, Finch CE, Krafft GA, Klein WL (1998) Diffusible, nonfibrillar ligands derived from Abeta1-42 are potent central nervous system neurotoxins. Proc Natl Acad Sci USA 95:6448-6453.

Lesne S, Ali C, Gabriel C, Croci N, MacKenzie ET, Glabe CG, Plotkine M, Marchand-Verrecchia C, Vivien D, Buisson A (2005) NMDA receptor activation inhibits alpha-secretase and promotes neuronal amyloid-beta production. J Neurosci 25:9367-9377.

Lue LF, Kuo YM, Roher AE, Brachova L, Shen Y, Sue L, Beach T, Kurth JH, Rydel RE, Rogers J (1999) Soluble amyloid beta peptide concentration as a predictor of synaptic change in Alzheimer's disease. Am J Pathol 155:853-862.

Ma T, Trinh MA, Wexler AJ, Bourbon C, Gatti E, Pierre P, Cavener DR, Klann E (2013) Suppression of eIF2alpha kinases alleviates Alzheimer's disease-related plasticity and memory deficits. Nat Neurosci 16:12991305.

Marciniak SJ, Garcia-Bonilla L, Hu J, Harding HP, Ron D (2006) Activationdependent substrate recruitment by the eukaryotic translation initiation factor 2 kinase PERK. J Cell Biol 172:201-209.

Martin LJ, Pardo CA, Cork LC, Price DL (1994) Synaptic pathology and glial responses to neuronal injury precede the formation of senile plaques and amyloid deposits in the aging cerebral cortex. Am J Pathol 145:13581381.

Melchor JP, Pawlak R, Strickland S (2003) The tissue plasminogen activatorplasminogen proteolytic cascade accelerates amyloid-beta (Abeta) degradation and inhibits Abeta-induced neurodegeneration. J Neurosci 23:8867-8871.

Mendez P, De Roo M, Poglia L, Klauser P, Muller D (2010) N-cadherin mediates plasticity-induced long-term spine stabilization. J Cell Biol 189:589-600.

Merino P, Diaz A, Jeanneret V, Wu F, Torre E, Cheng L, Yepes M (2017) Urokinase-type plasminogen activator (uPA) binding to the uPA receptor (uPAR) promotes axonal regeneration in the central nervous system. J Biol Chem 292:2741-2753.

Munshi HG, Ghosh S, Mukhopadhyay S, Wu YI, Sen R, Green KJ, Stack MS (2002) Proteinase suppression by E-cadherin-mediated cell-cell attachment in premalignant oral keratinocytes. J Biol Chem 277:38159-38167.

Nikitczuk JS, Patil SB, Matikainen-Ankney BA, Scarpa J, Shapiro ML, Benson DL, Huntley GW (2014) N-cadherin regulates molecular organization of excitatory and inhibitory synaptic circuits in adult hippocampus in vivo. Hippocampus 24:943-962.

Ozturk A, Minster RL, DeKosky ST, Kamboh MI (2007) Association of tagSNPs in the urokinase-plasminogen activator (PLAU) gene with Alzheimer's disease and associated quantitative traits. Am J Med Genet B Neuropsychiatr Genet 144B:79-82.
Pielarski KN, van Stegen B, Andreyeva A, Nieweg K, Jungling K, Redies C, Gottmann K (2013) Asymmetric N-cadherin expression results in synapse dysfunction, synapse elimination, and axon retraction in cultured mouse neurons. PLoS One 8:e54105.

Plant LD, Boyle JP, Smith IF, Peers C, Pearson HA (2003) The production of amyloid beta peptide is a critical requirement for the viability of central neurons. J Neurosci 23:5531-5535.

Prager GW, Breuss JM, Steurer S, Mihaly J, Binder BR (2004) Vascular endothelial growth factor (VEGF) induces rapid prourokinase (pro-uPA) activation on the surface of endothelial cells. Blood 103:955-962.

Price JL, Morris JC (1999) Tangles and plaques in nondemented aging and "preclinical" Alzheimer's disease. Ann Neurol 45:358-368.

Sanes JR, Yamagata M (1999) Formation of lamina-specific synaptic connections. Curr Opin Neurobiol 9:79-87.

Sasaki CY, Lin H, Passaniti A (1999) Regulation of urokinase plasminogen activator (uPA) activity by E-cadherin and hormones in mammary epithelial cells. J Cell Physiol 181:1-13.

Selkoe DJ (2002) Alzheimer's disease is a synaptic failure. Science 298:789791.

Selkoe DJ, Yamazaki T, Citron M, Podlisny MB, Koo EH, Teplow DB, Haass C (1996) The role of APP processing and trafficking pathways in the formation of amyloid beta-protein. Ann NY Acad Sci 777:57-64.

Shan W, Yoshida M, Wu XR, Huntley GW, Colman DR (2002) Neural (N-) cadherin, a synaptic adhesion molecule, is induced in hippocampal mossy fiber axonal sprouts by seizure. J Neurosci Res 69:292-304.

Shankar GM, Bloodgood BL, Townsend M, Walsh DM, Selkoe DJ, Sabatini BL (2007) Natural oligomers of the Alzheimer amyloid-beta protein induce reversible synapse loss by modulating an NMDA-type glutamate receptor-dependent signaling pathway. J Neurosci 27:2866-2875.

Sompol P, Furman JL, Pleiss MM, Kraner SD, Artiushin IA, Batten SR, Quintero JE, Simmerman LA, Beckett TL, Lovell MA, Murphy MP, Gerhardt GA, Norris CM (2017) Calcineurin/NFAT signaling in activated astrocytes drives network hyperexcitability in Abeta-bearing mice. J Neurosci 37:6132-6148.

Tanaka H, Shan W, Phillips GR, Arndt K, Bozdagi O, Shapiro L, Huntley GW, Benson DL, Colman DR (2000) Molecular modification of N-cadherin in response to synaptic activity. Neuron 25:93-107.

Terry RD, Masliah E, Salmon DP, Butters N, DeTeresa R, Hill R, Hansen LA, Katzman R (1991) Physical basis of cognitive alterations in Alzheimer's disease: synapse loss is the major correlate of cognitive impairment. Ann Neurol 30:572-580.

Togashi H, Abe K, Mizoguchi A, Takaoka K, Chisaka O, Takeichi M (2002) Cadherin regulates dendritic spine morphogenesis. Neuron 35:77-89.

Tucker HM, Kihiko M, Caldwell JN, Wright S, Kawarabayashi T, Price D, Walker D, Scheff S, McGillis JP, Rydel RE, Estus S (2000) The plasmin system is induced by and degrades amyloid-beta aggregates. J Neurosci 20:3937-3946

Uchida N, Honjo Y, Johnson KR, Wheelock MJ, Takeichi M (1996) The cate$\mathrm{nin} /$ cadherin adhesion system is localized in synaptic junctions bordering transmitter release zones. J Cell Biol 135:767-779.

Whelan CD, Mattsson N, Nagle MW, Vijayaraghavan S, Hyde C, Janelidze S, Stomrud E, Lee J, Fitz L, Samad TA, Ramaswamy G, Margolin RA, Malarstig A, Hansson O (2019) Multiplex proteomics identifies novel CSF and plasma biomarkers of early Alzheimer's disease. Acta Neuropathol Commun 7:169.

Zhai RG, Vardinon-Friedman H, Cases-Langhoff C, Becker B, Gundelfinger ED, Ziv NE, Garner CC (2001) Assembling the presynaptic active zone: a characterization of an active one precursor vesicle. Neuron 29:131-143. 